\title{
Equilibrium and Thermodynamic Studys of Adsorption of Azo Dyes on The Local Bentonite Clay
}

\author{
*Safwan.A.S.Aldbouni **Emad.A.S.Alhyali ***Ammar.A.H.Alkazraji \\ University of Mosul /College of Education for Pure Sciences/Department of \\ Chemistry \\ *Safwan76xxx@gmail.com/**emmadabd2006@yahoo.com/ \\ ***ammarhamdoon@unomosul.edu.iq \\ Received Accepted \\ 13/08/2018 17/09/2018
}

\begin{abstract}
This work is included the synthesizs of two azo dyes from the reaction of p-methoxy aniline and 2-amino benzo thiazol .via diazounium ions.A number of clays are tested as adsorbents for the removal of these dyes from their aqueous solution by adsorption . The most efficied one was selected to peforme this study. The prepared dyes are characterized by some of their physical propertier such as $\left(\lambda_{\max }\right),\left(\varepsilon_{\max }\right)$ melting point. Stretch bond of $(\mathrm{N}=\mathrm{N})$ group by(IR)spectrometry and colours.

The optimal condition of the adsorption systems undre study such as effect of does ,initial concentration , and temperature wear investigated .

Two isotherm models,Langmuir and Freundlich were fitted to the experimental data of adsorption .the thermodynamic Function $\left(\Delta \mathrm{H}, \Delta \mathrm{G}^{\circ}, \Delta \mathbf{S}^{\circ}\right)$ are estimated. The results of the thermodynamic study showed that ,the forces controlling the adsorption process of the systems under considerate are physical in nature. The adsorption process are exothermic, occur spontaneously in the direction of connecting the dye to the clay surface ,and forming less random system.
\end{abstract}

Keywords: thermodynamic, adsorption, azo dyes, bentonite clay 


\title{
دراسة اتزان و ثيرموداينمكية لامتزاز أصباغ الآزو على طين البنتونايت المحلي
}

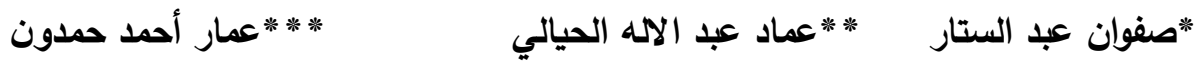 \\ جامعة الموصل/ كلية التربية للعلوم الصرفة / قسم الكيمياء \\ *Safwan76xxx@gmail.com/**emmadabd2006@yahoo.com/ \\ ***ammarhamdoon@unomosul.edu.iq
}

\section{تاريخ الاستلام تاريخ القبول \\ 2018/09/17 2018/08/13}

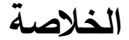

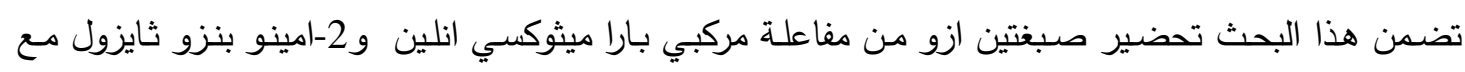

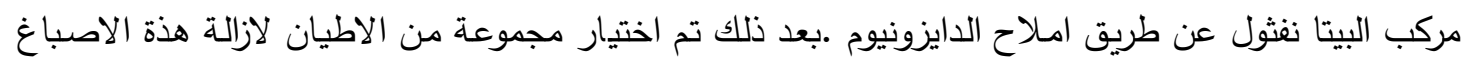

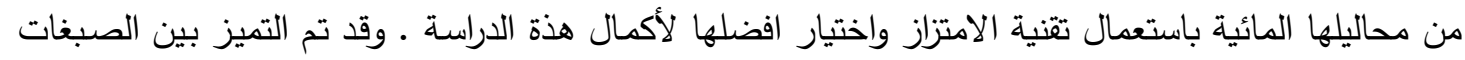

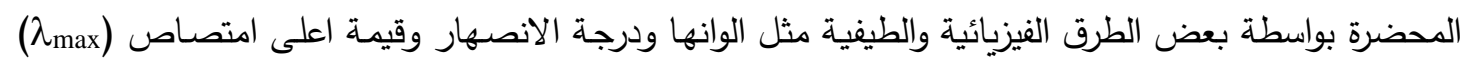

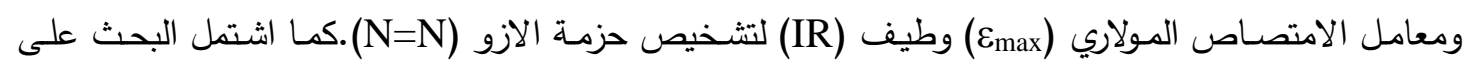

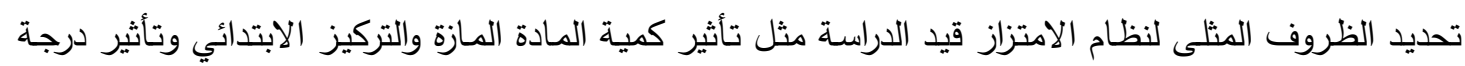

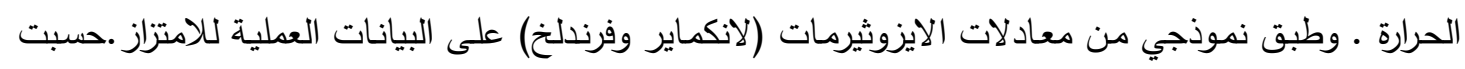

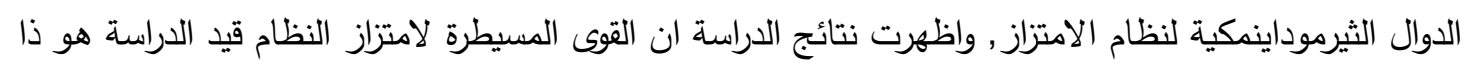

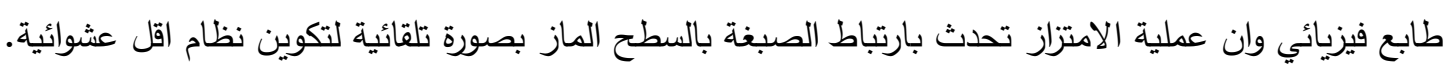

الكلمات المفتاحية : ثيرموداينميك ، امتزاز ، اصباغ الازو ، طين البنتونايت

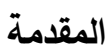

يعد التلوث من المشاكل الرئيسة التي تواجة البيئة والمجتمع والتي تؤثر على النظام المائي ويكون سببا اساسيا

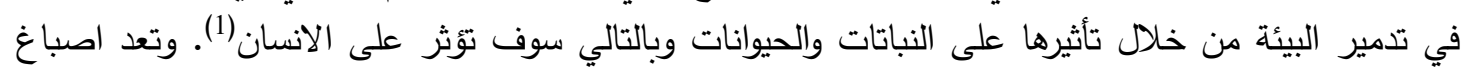

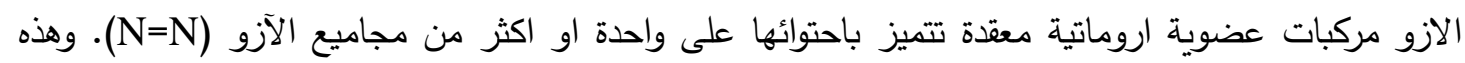

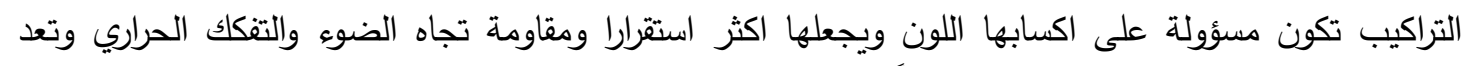

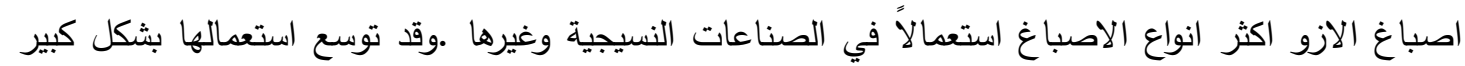

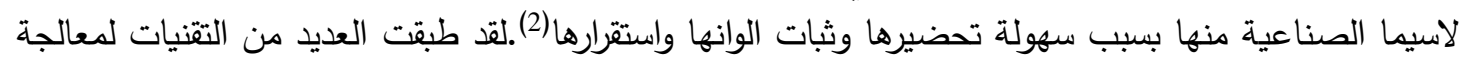

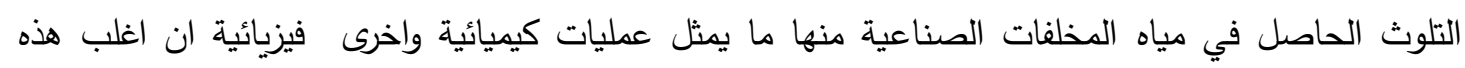
التقنيات تمتلك محددات سلبية تحول دون استعمالها حيث ان تطبيق قسم منها مكلف اقتصاديا او ماينتج منها

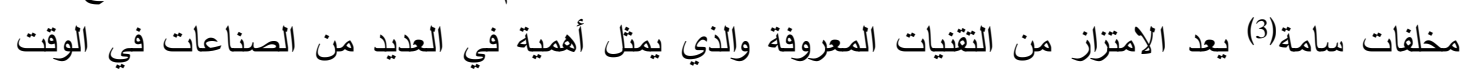


الحاضر والتي لا تستغني عنه في تطبيقاتها واستعمالاتها. فنلاحظ انه يستعمل في صناعات البترول والأصباغ

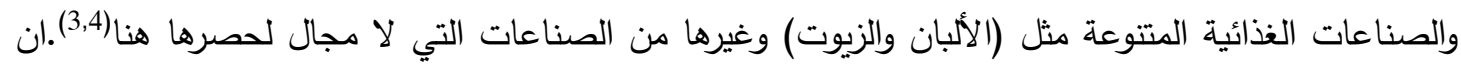

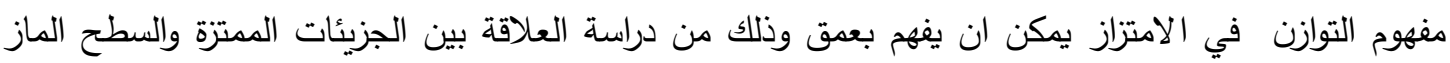

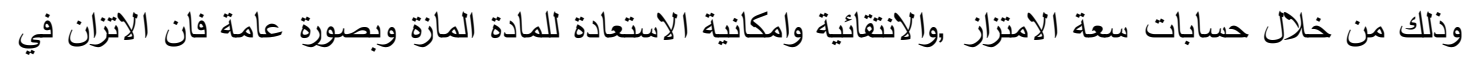

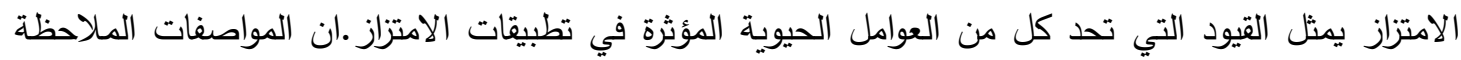

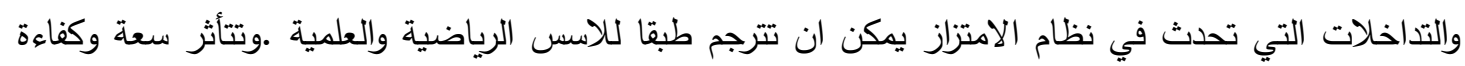

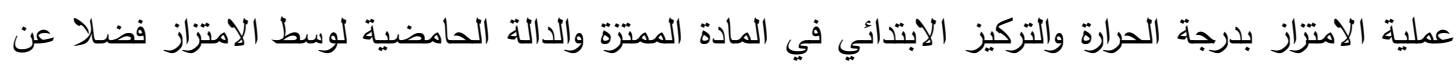

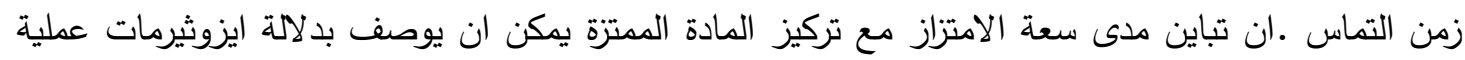

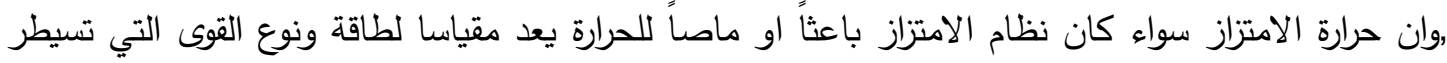

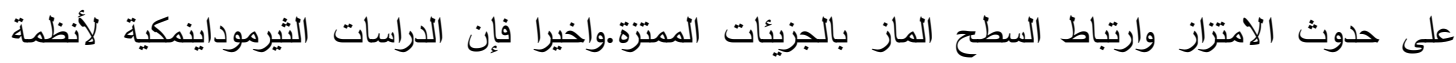
الامتزاز تساعد الباحثين في فهم الانظمة وتسهيل عملية تصميم الوحدات الريادية اللازمة لانجاز هذاته

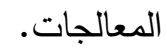

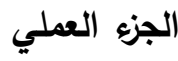

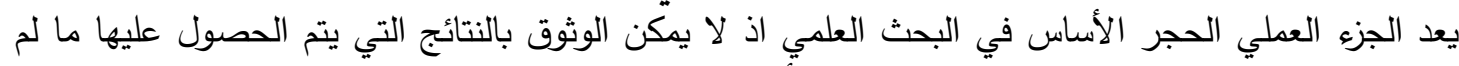

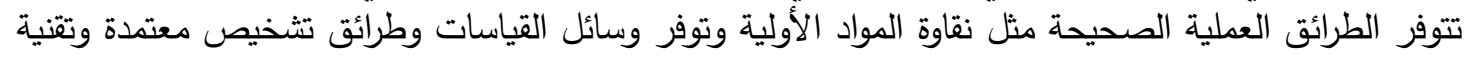
مناسبة لإجراء التجارب العلمية. وقد تضمن الجزء العملي من هذه الدراسة الخطوات التالية:

\section{1 تحضير الاصباغ قيد الدراسة}

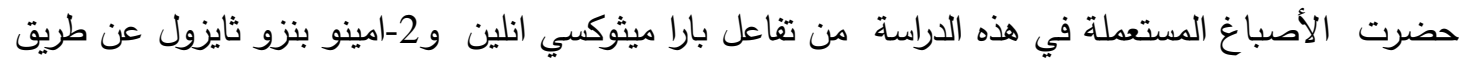
تفاعلات الأزوتة والاقتران ومن خلال تكوين املاح الديازونيوم وبخطوتين رئيستين هما:

الخطوة الأولى: تحضير أملاح الديازونيوم(5) حضرت أملاح الديازونيوم باتباع الخطوات الآتية: أ-اذيب (3.24g) من (بارا ميثوكسي انلين) في HCl (30ml المركز في بيكر وباستعمال التحريك باتيك

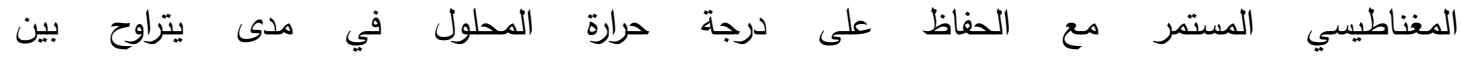
- $\left(\rho^{\circ} 5-0\right)$

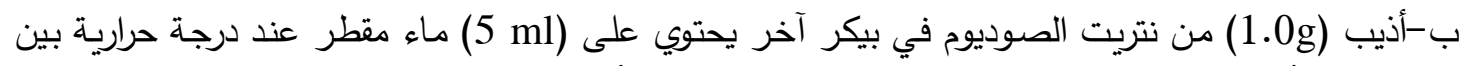

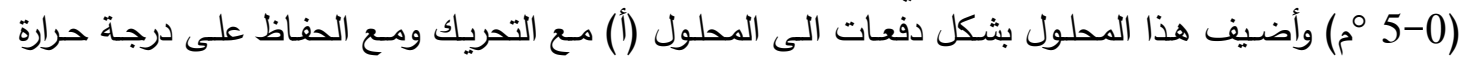

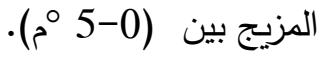

الخطوة الثانية: تحضير محلول B-naphthol حضر (10ml) من محلول هيدروكسيد الصوديوم بتركيز (10\%) بعد ذلك أذيب (2.2g) من البيتا نفثول في

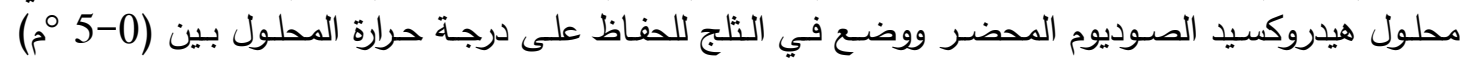

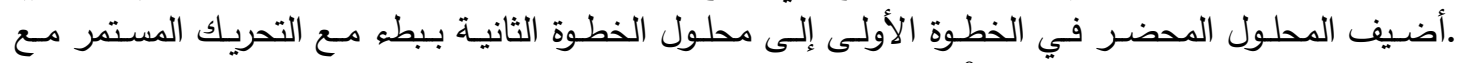

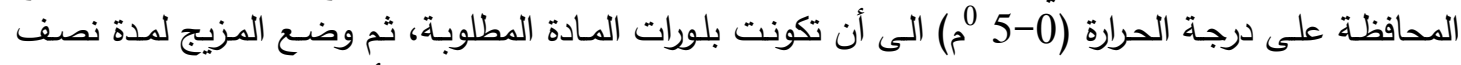

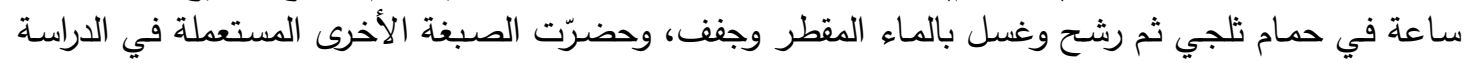
والموضحة في الجدول (1) بالطريقة نفسها. 


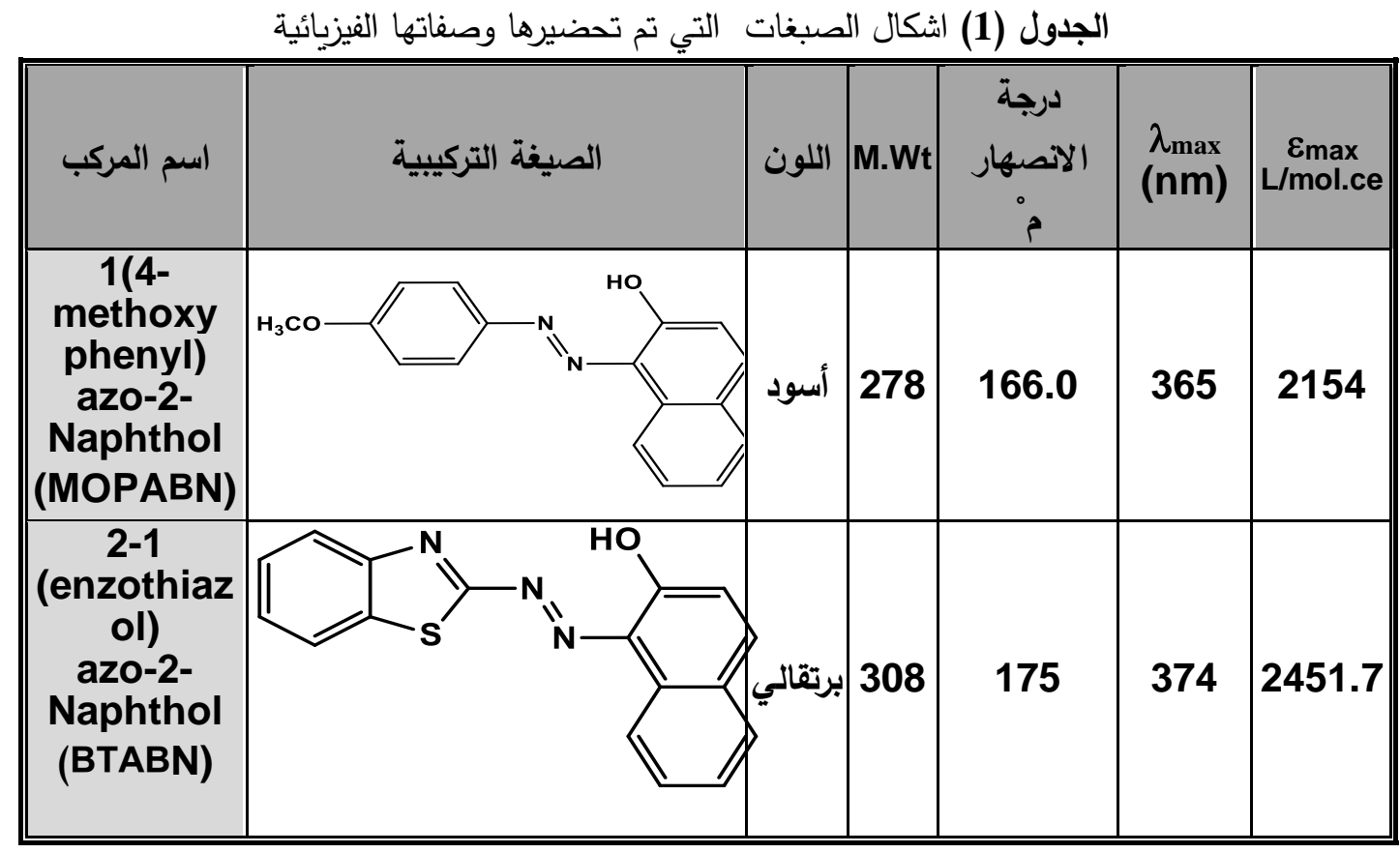

2. 2. أختبار المادة المازة قيد الدراسة

تم أختيار اطيان ( 1-بنتونايت الصحراء الغربية 2-بنتونايت قرة تبة 3-السلايت 4-الكاوؤلين 5- اييوكسايد 6-

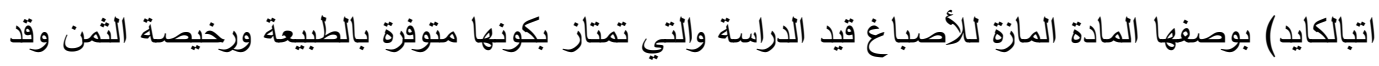
استعملت هذه الاطيان جميعها على شكل باودر بعد معالجتها واعدادها كما يلي : 1- تم سحق الطين ووضعة في بيكر كبير بالماء المقطر بثكل عالق لفصل الاجزاء الرملية وغير الطينية لعملية

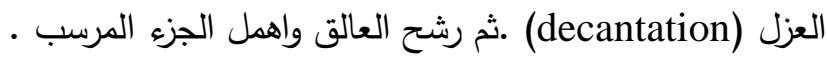
2-تم غسل هذه الأطيان مرات عدة بالماء المقطر ثم ترشيحها. 3-تركت النماذج لتجف بتعرضها لحرارة الثمس ثم حفظ الانموذج في عبوات محكمة الغلق لغرض حفظها من

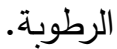

4-استعملت هذه النماذج المحضرة من الأطيان في دراسة عملية امتزاز الصبغات قيد الدراسة وهي بثكل محلول

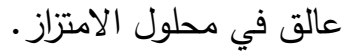

نشطت الأنواع الستة من الأطيان المعالجة قيد الدراسة حرارياً وذلك من خلال الخطوات التالية: أ-وضعت هذه الأطيان في فرن كهربائي خاص وبدرجات حرارية مختلفة (100-500॰م) وبزيادة (100 ماعم) ولمدة (24) ساعة. ب-حفظت هذه النماذج في عبوات مغلقة كي تبقى جافة لحين استعمالها في دراسة عملية امتزاز الأصباغ قيد الدراسة.

\section{3.}

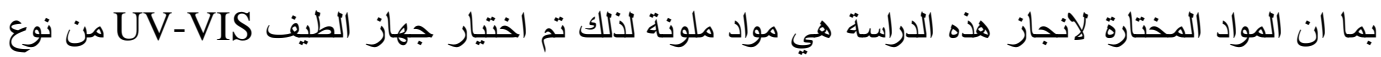

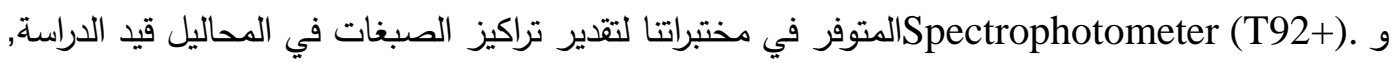

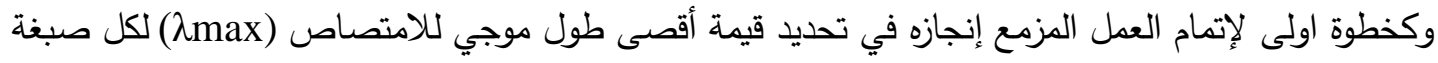
والتي عندها يتم تتبع تغير كمية المادة الممتزة مع الزمن وحسب طبيعة كل دراسة. ولإنجاز هذا العمل استعمل 
قانون بير لامبرت Lambert law Beer`s لعمل منحني معايرة عند قيمة العاس لكل صبغة وذلك من رسم العلاقة بين الامتصاص والتركيز وحسب المعادلة:

$\mathrm{A}=\varepsilon \mathrm{CL}$

إذ ان (A) تمثل الامتصاص و (ع) هو معامل الامتصاص المولاري

(Liter.mol $\left.{ }^{-1} . \mathrm{cm}^{-1}\right)$

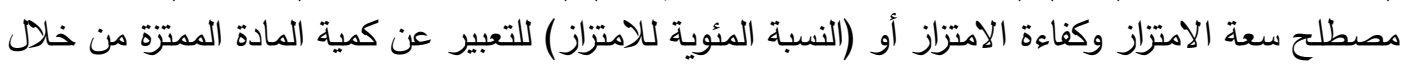

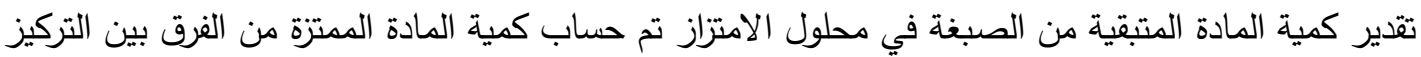

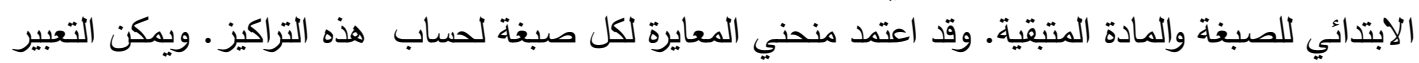
عن سعة امتزاز (qe) المادة المازة للصبغة بادة المعادلة الآتية

qe (Adsorption capacity) (mg/g) = $\frac{C_{i}-C_{e}}{M} \times \mathrm{V}-----(2)$

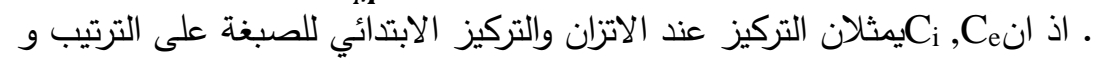

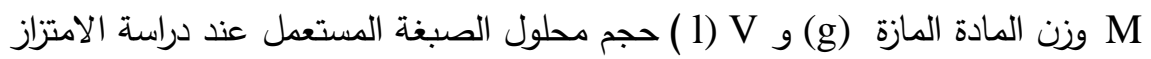
كما يمكن حساب النسبة المئوية للصبغة المزالة (الممتزة) أو ما يسمى لكمفاءة الامتزاز باستخدام المعادلة الآتية: $\%$ Adsorption $=\frac{C_{i}-C_{e}}{C_{i}} \times 100$

4. دراسة عملية الامتزاز بطريقة الدفعة الواحدة

انجزت هذة الدراسة من خلال استعمال طريقة الدفعة الواحدة والتي يمكن انجازها عن طريق رج كميات محددة

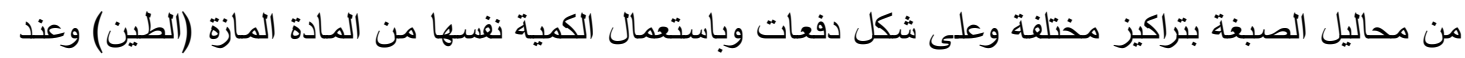

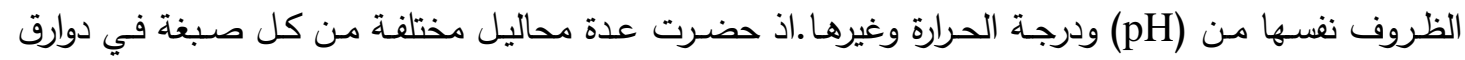

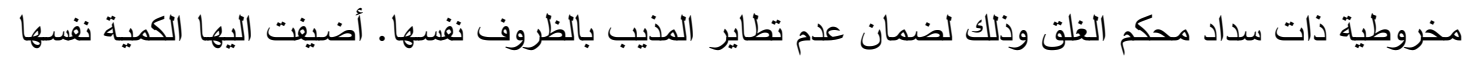

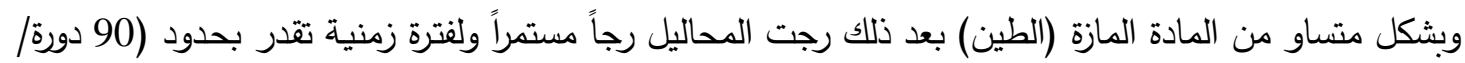

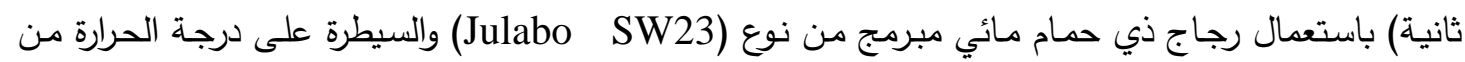

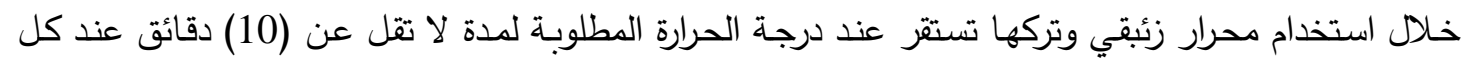

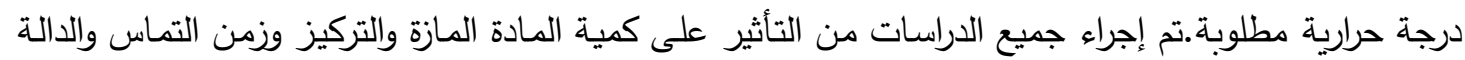
الحامضية وكذلك تاثير درجة الحرارة والدراسة الحركية على طريقة الدفعة الواحدة.

5. - 5ساب الدوال الثيرمود/ينميكية

حسبت قيم ثابت توازن الامتزاز (K) عند درجات حرارية مختلفة عند حالة الاتزان من النسبة بين تركيز المادة

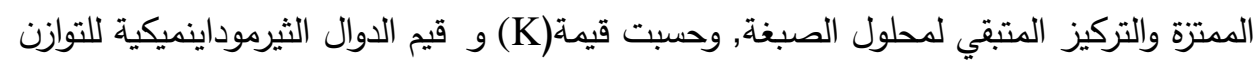
باستعمال المعادلات التالية.

$K=\frac{C_{a d}(m g / l)}{C_{e}(m g / l)}$

$\operatorname{Ln} \mathrm{K}=\ln \mathrm{K}^{\circ}-\frac{\Delta \mathrm{H}}{\mathrm{RT}}$

$\Delta \mathrm{G}^{\circ}=-\mathrm{RT}$ In $\mathrm{K}$

$\Delta \mathrm{G}^{\circ}=\Delta \mathrm{H}-\mathrm{T} \Delta \mathrm{S}^{\circ}$

$\Delta \mathrm{S}^{\circ}=\left(\Delta \mathrm{H}-\Delta \mathrm{G}^{\circ}\right) / \mathrm{T}$

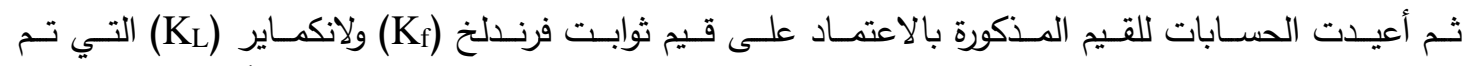
ايجادها من تطبيق هذه الايزوثيرمات على البيانات العملية للامتزاز وكما سيتم توضيحها لاحقاً 
6. - ايزوثيرمات الامتزاز

تم تطبيق ايزوثيرمات فرندلخ ولانكماير على البيانات العملية المحصل عليها من دراسة نظام الامتزاز قيد الدراسة

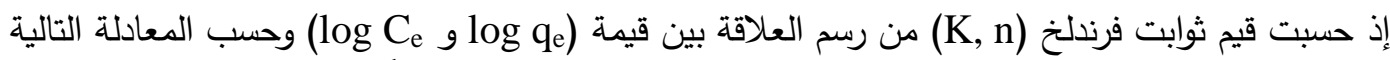
$\log q_{e}=\log K_{f}+\frac{1}{n} \log C_{e}$

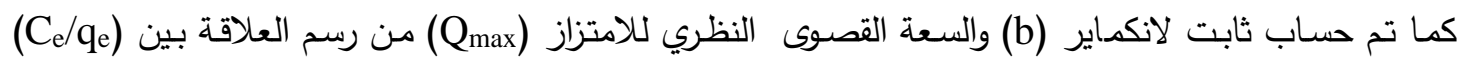
مقابل (Ce) وحسب المعادلة التالية

$\frac{C_{e}}{q_{e}}=\frac{1}{b Q_{\max }}+\frac{C_{e}}{Q_{\max }}$

وقد استعمل برنامج (Excel) لانجاز الرسوم البيانية واللازمة لحساب القيم المذكورة في هذه الفقرة.

\section{النتائج والمناقثة}

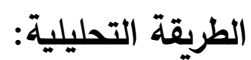

إن الأصباغ قيد الدراسة هي مواد ملونة فالطريقة الطيفية تعد الخيار الأمثل لانجاز هذة الدراسة وكخطوة أولية

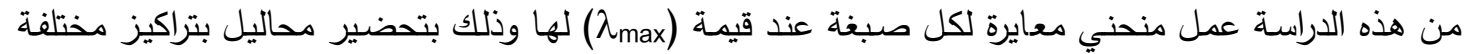

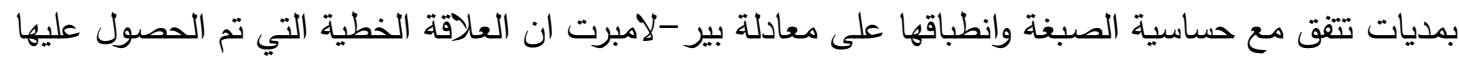
من تطبيق معادلة بير -لامبرت والمشار إليها بقيم معاملات الارتباط (R2) الجيدة تدل على على إمكانية تطبيق هذاته

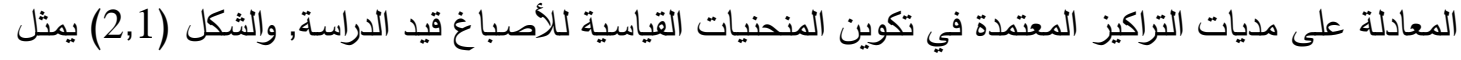
تطبيق معادلة بير لامبرت لإنجاز منحني المعايرة للصبغات قيد للدراسة.

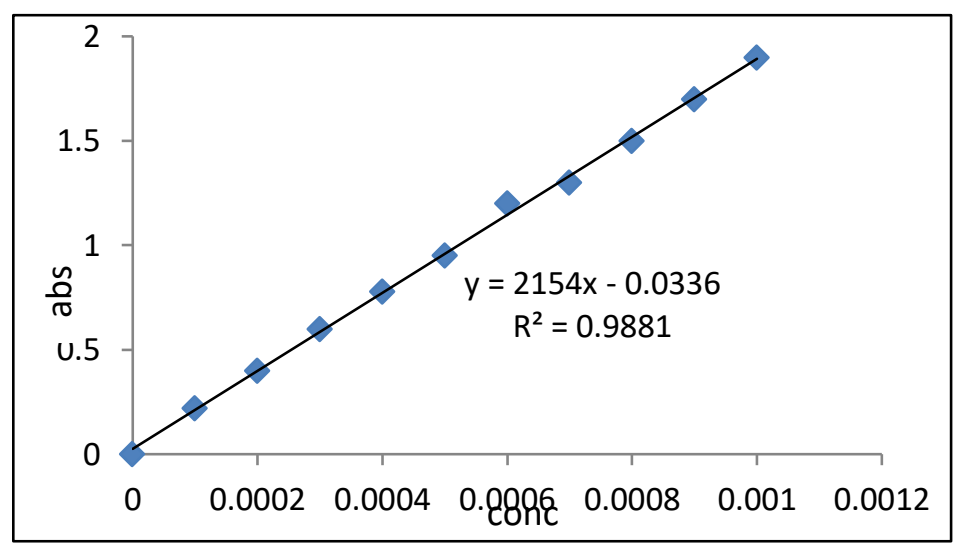

الثكل (1) منحني المعايرة للصبغة MOPBN 


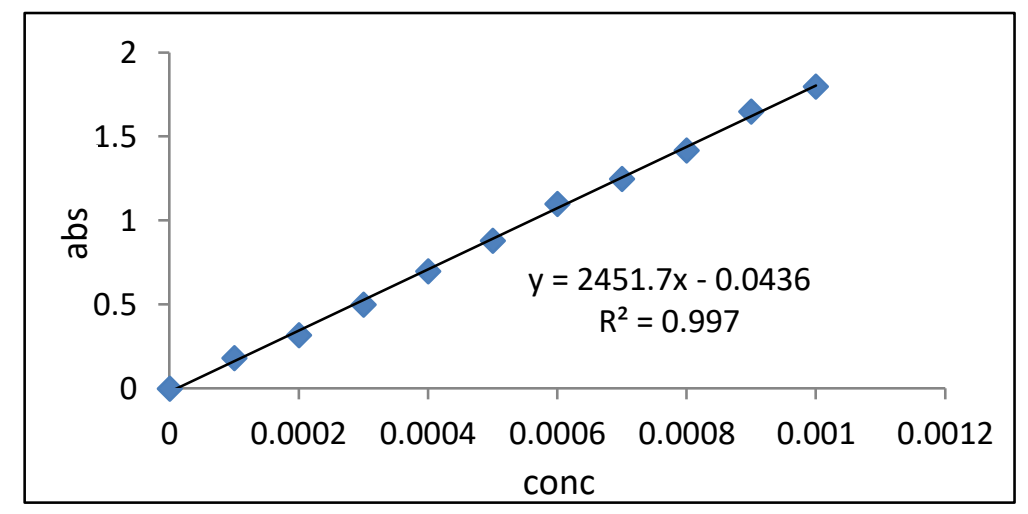

الشكل (2) منحني المعايرة للصبغة BTABN

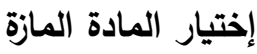
وفي بحثا هذا تم اختيار عدد من الأطيان منها السلايت والكاؤولين والايبوكسايت وبنتونايت قرة تبه والاتابلكايد فضلاً عن بنتونايت الصحراء الغربية. الجدول من (2) تمثل اختيار نماذج من هذه الأطيان (غير المعالج) والتي

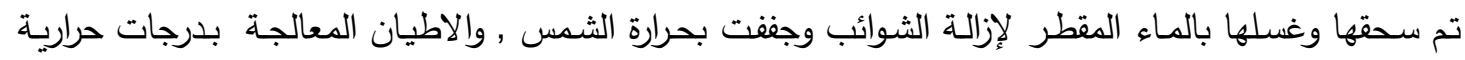
مختلفة (مْ 100,200,300,400,500 ), وعزلها بحجم مناسب للدقائق المكونة لها باستعمال المناخل الجزيئية وبعملية الامتزاز بطريقة الدفعة الواحدة (Batch Method) للصبغات المحضرة في هذه الدراسة.

الجدول(2) دراسة امتزاز عدد من الأطيان الغير معالجة والمعالجة حراريا مع مركب (MOPABN) وبدرجة

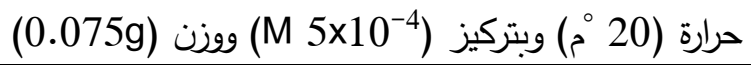

\begin{tabular}{|c|c|c|c|c|c|c|}
\hline \multirow[t]{2}{*}{ اسم الطين } & \multirow[t]{2}{*}{ غير معالج } & \multicolumn{5}{|c|}{ معالجة بدرجات حرارية (م) } \\
\hline & & 100 & 200 & 300 & 400 & 500 \\
\hline \%Bentonite(w) & 54.6 & 58.3 & 56.2 & 63.4 & 71.4 & 33.4 \\
\hline \%Attapulgit & 40.5 & 42.1 & 35.6 & 58.2 & 63.9 & 28.2 \\
\hline \%Bentonite(k.t) & 31.6 & 42.6 & 45 & 51.4 & 52.3 & 20 \\
\hline \%Bauxite & 18.2 & 34 & 38.6 & 46.2 & 26.5 & 10.2 \\
\hline$\%$ Celite & 11.8 & 12.7 & 14.1 & 14.6 & 14.7 & 6.2 \\
\hline \%kaolin & 11.8 & 11.9 & 12.3 & 12.8 & 19.4 & 10.7 \\
\hline
\end{tabular}

عند النظر إلى النتائج المصل عليها في الجدول نلاحظ أن طين بينتونايت الصحراء الغربية أعطى أعلى نسبة

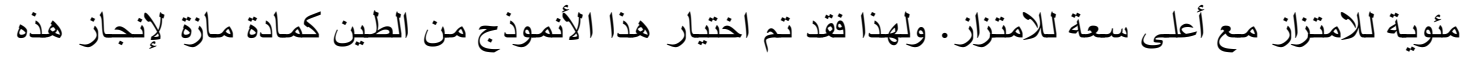

تأثير كمية المادة المازة:

إن الغرض من إجراء هذه الدراسة هو إيجاد كمية مناسبة من المادة المازة والتي تحقق حالة الاتزان للنظام مع

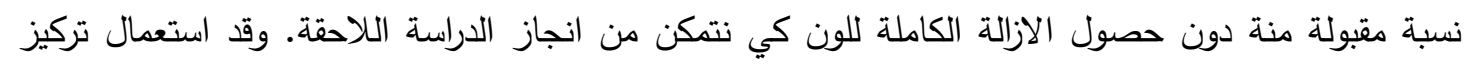

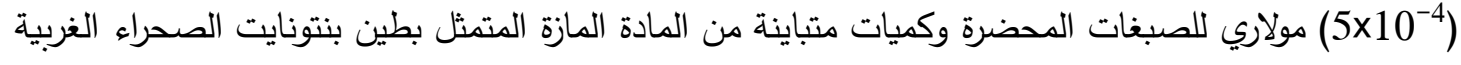

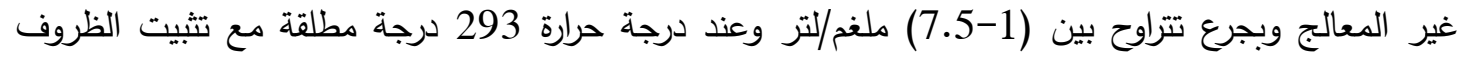

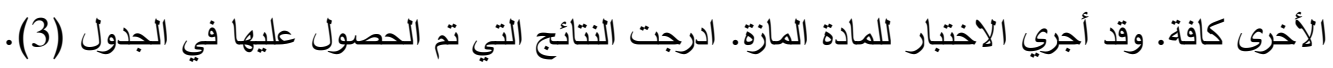


الجدول (3) تأثير كمية الطين المستعمل (بنتونايت الصحراء الغربية) غير المعالج على سعة الامتزاز والنسبة المئوية وعند ودرجة حرارة (20 إم م) وعند تركيز (5x10 M)

\begin{tabular}{|c|c|c|c|c|c|}
\hline اسم المركب & $\mathrm{C}_{\mathrm{i}}(\mathrm{mg} / \mathrm{l})$ & $\mathrm{C}_{\mathrm{e}}(\mathrm{mg} / \mathrm{l})$ & $\begin{array}{c}\text { Dose }(\mathrm{mg} / \mathrm{l}) \\
\text { of Adsor }\end{array}$ & $\mathrm{q}_{\mathrm{e}}(\mathrm{mg} / \mathrm{g})$ & النسبة المتئوية \\
\hline MOPABN & 139 & $\begin{array}{l}90 \\
85 \\
73 \\
63 \\
\end{array}$ & $\begin{array}{c}1 \\
2.5 \\
5 \\
7.5 \\
\end{array}$ & $\begin{array}{c}245 \\
108 \\
66 \\
50.6\end{array}$ & $\begin{array}{l}35.2 \\
38.8 \\
47.4 \\
54.6 \\
\end{array}$ \\
\hline BTABN & 154 & $\begin{array}{c}116 \\
95 \\
83 \\
73\end{array}$ & $\begin{array}{c}1 \\
2.5 \\
5 \\
7.5\end{array}$ & $\begin{array}{c}190 \\
118 \\
71 \\
54\end{array}$ & $\begin{array}{l}24.6 \\
38.3 \\
46.1 \\
52.5\end{array}$ \\
\hline
\end{tabular}

من ملاحظة الجدول (3) نجد أن سعة الامتزاز وعند تركيز (5x10-4) مولاري من الصبغات تقل قيمتها فيما

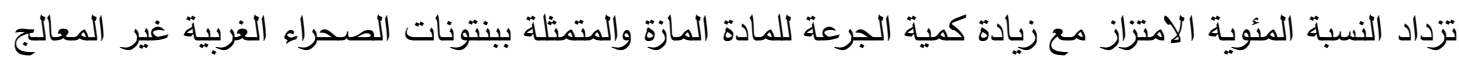
ويمكن تفسير هذا التباين من خلال منظورين. الأول هو أنه بزيادة كمية المادة المازة فإن عدد المواقع المؤهلة للامتزاز سوف تزداد ويرافق ذلك زيادة في كفاءة

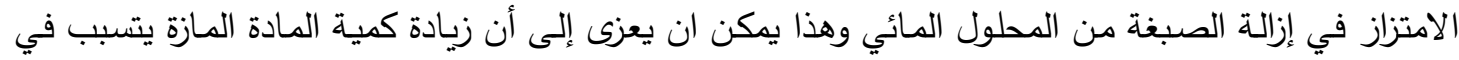

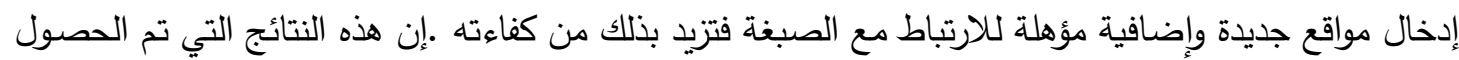
عليها تتفق مع نتائج أخرى قد شوهدت في دراسات أخرى مماثلة في الأدبيات (7,6).

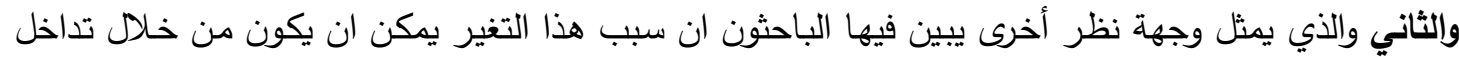

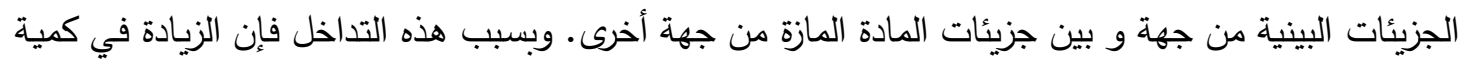

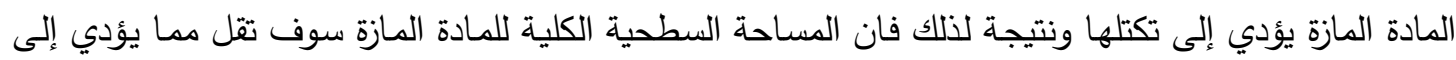

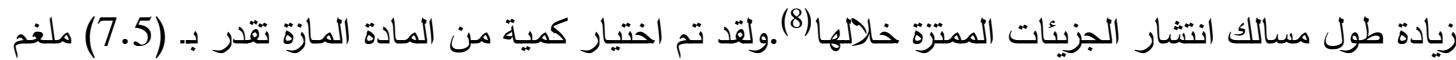

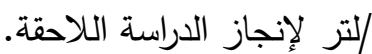

تأثير المذيب على الامتزاز: بما ان الصبغات المختارة لهذة الدراسة قليلة الذوبان في الماء ولأجل إنجاز هذه الدراسة كان لابد من اختيار

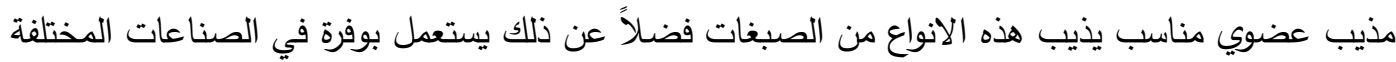
وكذلك رخيص الثمن والهدف من استعمال المذيب العضوي هو لايجاد خليط منه مع الماء وباقل كمية ممكنة

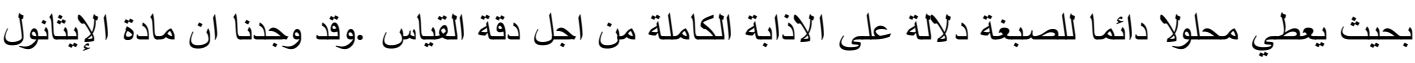

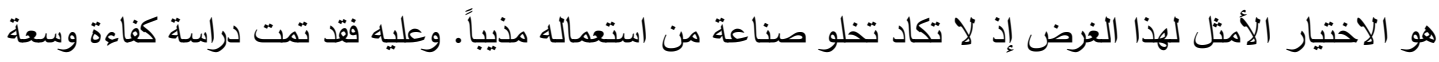

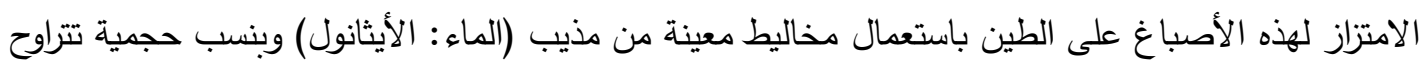
فيها كمية الأيثانول من (10-80\%). 
الجدول (4) تأثير المذيب على النسبة المئوية للامتزاز وعند وزن (0.075g) من طين (بنتونايت الصحراء الغربية)

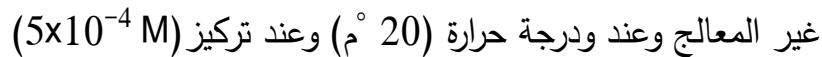

\begin{tabular}{|c|c|c|c|c|c|}
\hline أسم المركب & النسبة المئوية & النسبة المئوية & $\underset{(\mathrm{mg} / \mathrm{l})}{\mathrm{C}_{\mathrm{e}}}$ & $\underset{(\mathrm{mg} / \mathrm{g})}{\mathrm{qe}_{\mathrm{e}}}$ & الامتزبة المئوية \\
\hline \multirow{5}{*}{ MOPABN } & 10 & 90 & 95 & 29.3 & 31.6 \\
\hline & 20 & 80 & 68.4 & 47.3 & 50.7 \\
\hline & 30 & 70 & 63 & 50.6 & 54.6 \\
\hline & 50 & 50 & 65.2 & 49.2 & 53.0 \\
\hline & 80 & 20 & 83.9 & 36.7 & 40.7 \\
\hline \multirow{5}{*}{ BTABN } & 10 & 90 & 102 & 34.6 & 33.7 \\
\hline & 20 & 80 & 75.4 & 52.4 & 51.0 \\
\hline & 30 & 70 & 73 & 54.0 & 52.5 \\
\hline & 50 & 50 & 78.2 & 50.5 & 49.2 \\
\hline & 80 & 20 & 86.1 & 45.2 & 44.0 \\
\hline
\end{tabular}

واستنادا الى النتائج المدرجة في الجدول (4) نجد ان افضل نسبة من المذيب ايثانول : ماء والتي تحققت لنا

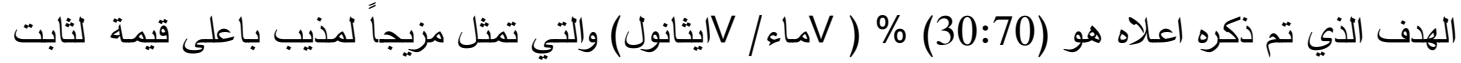

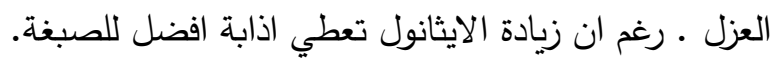

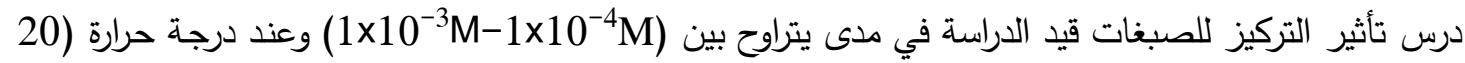

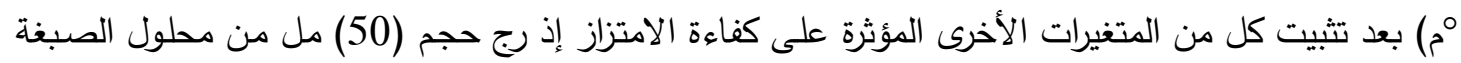

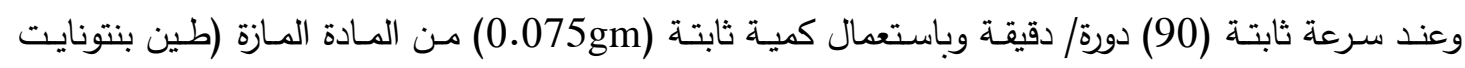

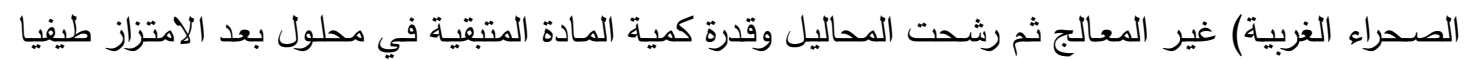
وعند قيم (2) لكل صبغة. والنتائج التي تم الحصول عليها من هذه الدراسة تم إدراجها في الجدول (5) 
الجدول (5) تأثير التركيز الابتدائي على النسبة المئوية للامتزاز ووزن (0.075g) من بنتونايت الصحراء الغربية غير المعالج وعند درجة حرارية (20 مْ).

\begin{tabular}{|c|c|c|c|c|}
\hline أسم المركب & $\mathrm{C}_{\mathrm{i}}(\mathrm{mg} / \mathrm{l})$ & $\mathrm{Ce}_{\mathrm{e}}(\mathrm{mg} / \mathrm{l})$ & $q_{e}(\mathrm{mg} / \mathrm{g})$ & النسبة المئوية الامتزاز \% \\
\hline \multirow{10}{*}{ MOPABN } & $1 \times 10^{-3}$ & 243 & 23.3 & 12.5 \\
\hline & $9 \times 10^{-4}$ & 216 & 22.8 & 13.6 \\
\hline & $8 \times 10^{-4}$ & 167.2 & 36.8 & 24.8 \\
\hline & $7 \times 10^{-4}$ & 113.6 & 54.0 & 41.6 \\
\hline & $6 \times 10^{-4}$ & 90.3 & 50.7 & 45.7 \\
\hline & $5 \times 10^{-4}$ & 63 & 50.6 & 54.6 \\
\hline & $4 \times 10^{-4}$ & 57.2 & 36.0 & 48.5 \\
\hline & $3 \times 10^{-4}$ & 44.6 & 25.8 & 46.5 \\
\hline & $2 \times 10^{-4}$ & 32.1 & 15.6 & 42.2 \\
\hline & $1 \times 10^{-4}$ & 16.7 & 7.4 & 39.9 \\
\hline \multirow{10}{*}{ BTABN } & $1 \times 10^{-3}$ & 219 & 59.3 & 28.8 \\
\hline & $9 \times 10^{-4}$ & 166.2 & 74.0 & 40.0 \\
\hline & $8 \times 10^{-4}$ & 145 & 67.6 & 41.1 \\
\hline & $7 \times 10^{-4}$ & 140 & 50.4 & 35.0 \\
\hline & $6 \times 10^{-4}$ & 95.7 & 59.4 & 48.2 \\
\hline & $5 \times 10^{-4}$ & 73.0 & 54 & 52.5 \\
\hline & $4 \times 10^{-4}$ & 63.5 & 39.8 & 48.4 \\
\hline & $3 \times 10^{-4}$ & 48.1 & 29.5 & 47.4 \\
\hline & $2 \times 10^{-4}$ & 40.5 & 14.0 & 34.2 \\
\hline & $1 \times 10^{-4}$ & 20.3 & 7.0 & 34.0 \\
\hline
\end{tabular}

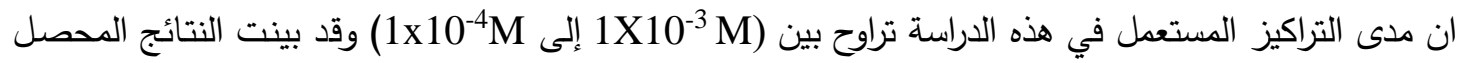

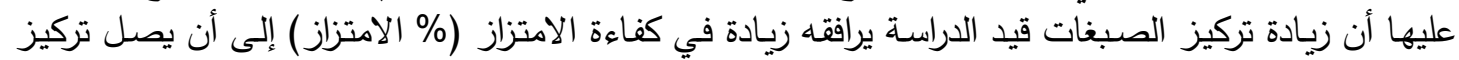
(5X10-4M)

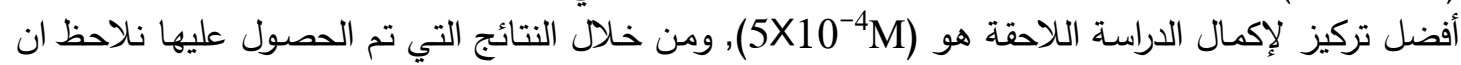

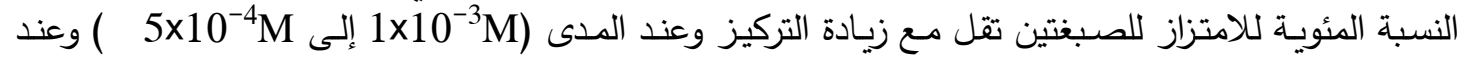

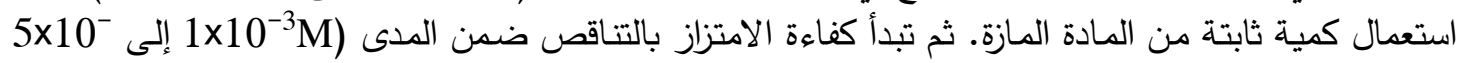

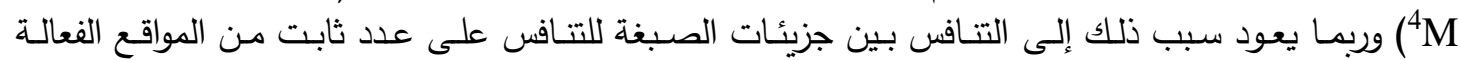

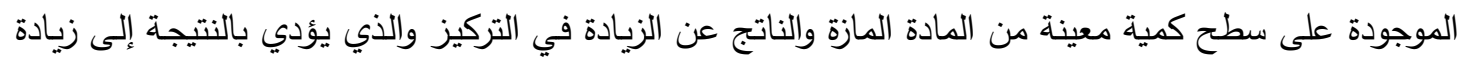

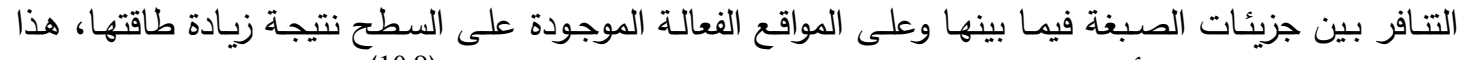
السلوك في هذا المدى الأخيرة يتقق مع ما تم الحصول عليه في في دراسات سابقة

تأثير الدالة الحامضية لوسط الامتزاز : أنائز

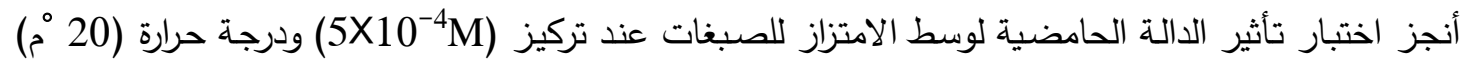

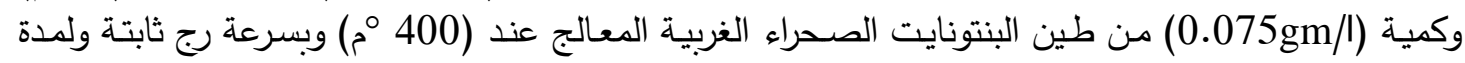

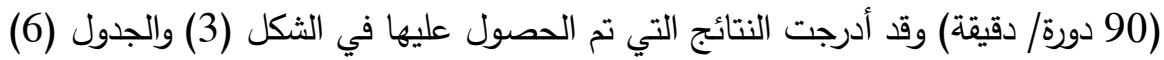


الجدول (6) يوضح تأثير الدالة الحامضية على النسبة المئوية للامتزاز للصبغات قيد الدراسة

\begin{tabular}{|c|c|c|c|c|}
\hline أسم المركب & pH & $\mathrm{C}_{\mathrm{e}}(\mathrm{mg} / \mathrm{l})$ & $q_{e}(m g / g)$ & للامتزاز المئوبة \\
\hline \multirow{4}{*}{ MOPABN } & 4 & 85.1 & 49.2 & 53.1 \\
\hline & 6 & 43.4 & 63.7 & 68.7 \\
\hline & $* 6.5$ & 40.1 & 65.9 & 71.1 \\
\hline & 9 & 58.3 & 53.8 & 58.0 \\
\hline \multirow{4}{*}{ BTABN } & 4 & 80.4 & 49.0 & 47.7 \\
\hline & 6 & 50.7 & 68.8 & 67.0 \\
\hline & $* 6.9$ & 43.6 & 73.6 & 71.6 \\
\hline & 9 & 55.3 & 65.8 & 64.0 \\
\hline
\end{tabular}

(*) تمثل الدالة الحامضية الطبيعية للصبغات.

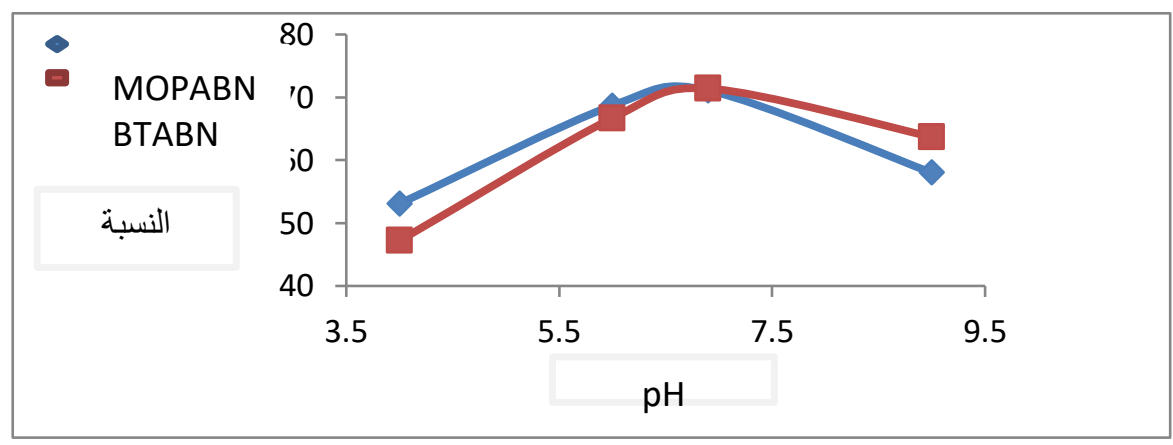

الشكل (3) يوضح العلاقة بين النسبة المئوية للامتزاز والدالة الحامضية للصبغات

عند ملاحظة الجدول (6) والثكل (3) نجد أن كفاءة وسعة الامتزاز تكون أعلى مايمكن عند الدالة الحامضية

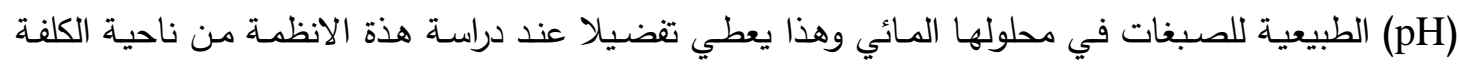
الاقتصادية.

3 درس تأثير درجة الحرارة على الصبغات قيد البحث وعند تركيز ابتدائي

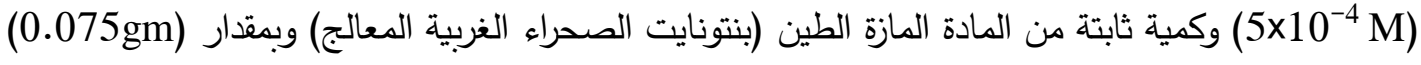

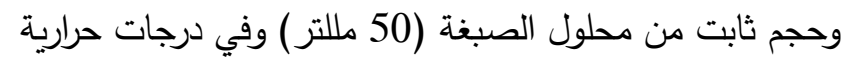

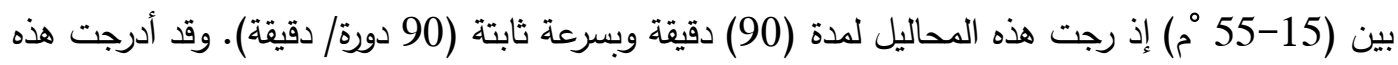
النتائج التي حصلنا عليها بالجداول الآتية: 
الجدول (7) تأثير درجة الحرارة على النسبة المئوية للامتزاز للصبغة (MOABN) ووزن (0.075g) من

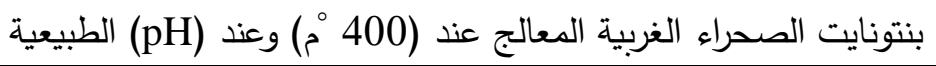

\begin{tabular}{|c|c|c|c|c|}
\hline $\mathrm{C}_{\mathrm{i}}(\mathrm{mg} / \mathrm{l})$ & $\operatorname{Tem}\left(K^{\circ}\right)$ & $\mathrm{C}_{\mathrm{e}}(\mathrm{mg})$ & $\mathrm{q}_{\mathrm{e}}(\mathrm{mg} / \mathrm{g})$ & النسبة المئوية للامتزاز \% \\
\hline \multirow{5}{*}{$6 \times 10^{-4}$} & 288 & 50.0 & 77.8 & 70.0 \\
\hline & 293 & 50.8 & 77.3 & 69.5 \\
\hline & 303 & 51.3 & 77.0 & 69.2 \\
\hline & 313 & 51.6 & 76.8 & 69.0 \\
\hline & 323 & 52.3 & 76.3 & 68.6 \\
\hline \multirow{5}{*}{$5 \times 10^{-4}$} & 288 & 39.5 & 66.3 & 71.5 \\
\hline & 293 & 40.1 & 65.9 & 71.1 \\
\hline & 303 & 40.3 & 65.8 & 71.0 \\
\hline & 313 & 40.9 & 65.4 & 70.5 \\
\hline & 323 & 41.3 & 64.7 & 69.8 \\
\hline \multirow{5}{*}{$4 \times 10^{-4}$} & 288 & 35.0 & 50.8 & 68.5 \\
\hline & 293 & 36.2 & 50.0 & 67.4 \\
\hline & 303 & 36.5 & 49.8 & 67.1 \\
\hline & 313 & 37.6 & 49.7 & 67.0 \\
\hline & 323 & 39.1 & 48.0 & 64.8 \\
\hline \multirow{5}{*}{$3 \times 10^{-4}$} & 288 & 30.0 & 35.6 & 64.0 \\
\hline & 293 & 31.5 & 34.6 & 62.2 \\
\hline & 303 & 32.8 & 33.7 & 60.6 \\
\hline & 313 & 33.1 & 33.5 & 60.2 \\
\hline & 323 & 34.6 & 32.5 & 58.5 \\
\hline
\end{tabular}


الجدول (8) تأثير درجة الحرارة على النسبة المئوية للصبغة (BTABN) ووزن (0.075g) من بنتونايت الصحراء الغربية المعالج عند (400 مْم) وعند (pH) الطبيعية.

\begin{tabular}{|c|c|c|c|c|}
\hline$C_{i}(\mathrm{mg} / \mathrm{l})$ & $\operatorname{Tem}\left(K^{\circ}\right)$ & $\mathrm{C}_{\mathrm{e}}(\mathrm{mg})$ & $q_{e}(\mathrm{mg} / \mathrm{g})$ & النسبة المئوية للامتزاز \% \\
\hline \multirow{5}{*}{$6 \times 10^{-4}$} & 288 & 50.0 & 89.6 & 72.9 \\
\hline & 293 & 51.3 & 89.0 & 72.2 \\
\hline & 303 & 51.6 & 88.8 & 72.0 \\
\hline & 313 & 52.8 & 88.0 & 71.4 \\
\hline & 323 & 54.1 & 87.1 & 70.7 \\
\hline \multirow{5}{*}{$5 \times 10^{-4}$} & 288 & 41.0 & 75.3 & 73.3 \\
\hline & 293 & 43.6 & 73.6 & 71.6 \\
\hline & 303 & 43.8 & 73.4 & 71.5 \\
\hline & 313 & 44.3 & 73.1 & 71.2 \\
\hline & 323 & 45.8 & 72.1 & 70.2 \\
\hline \multirow{5}{*}{$4 \times 10^{-4}$} & 288 & 40.2 & 55.3 & 67.3 \\
\hline & 293 & 41.8 & 54.2 & 66.0 \\
\hline & 303 & 42.0 & 54.1 & 65.9 \\
\hline & 313 & 42.5 & 53.8 & 65.5 \\
\hline & 323 & 43.6 & 53.0 & 64.6 \\
\hline \multirow{5}{*}{$3 \times 10^{-4}$} & 288 & 34.0 & 38.9 & 63.2 \\
\hline & 293 & 35.1 & 38.2 & 62.0 \\
\hline & 303 & 35.4 & 38.0 & 61.6 \\
\hline & 313 & 36.0 & 37.6 & 61.0 \\
\hline & 323 & 37.2 & 36.8 & 59.7 \\
\hline
\end{tabular}

عند النظر إلى الجدولين السابقين بدقة نلاحظ الآتي: 1- ضمن الصبغة الواحدة وباستعمال تركيز ثابت نجد أن زيادة درجة الحرارة في المدى المذكور يقلل من سعة الهن

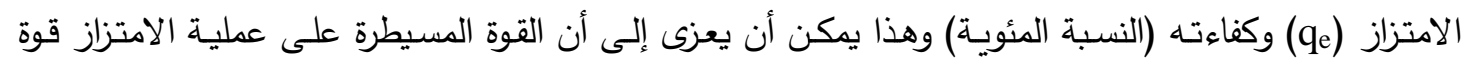
ضعيفة وأن زيادة درجة الحرارة في المدى المذكور تعمل على تكسير القوى التي تربط بين الصبغة والسطح الماز مما يحفز عودة جزيئات الصبغة إلى المحلول وبذلك تقل كفاءة الامتزاز وتقل عدد الجزيئات المرتبطة بالسطح

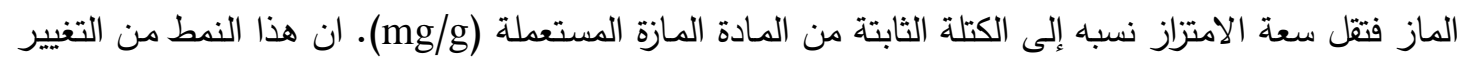
يمكن أن يعطي إثارة إلى أن القوى الرابطة بين جزيئات الصبغة وسطح الطين المعالج (400 من م) المستعمل هي من نوع القوى الضعيفة مثل قوى فاندرفالز وان عملية الامتزاز في النظام الددروس هي ذات ذات طابع فيزيائي.

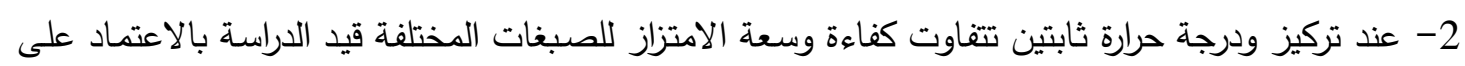

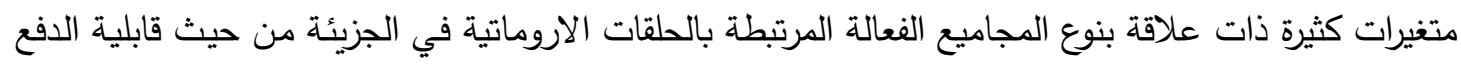

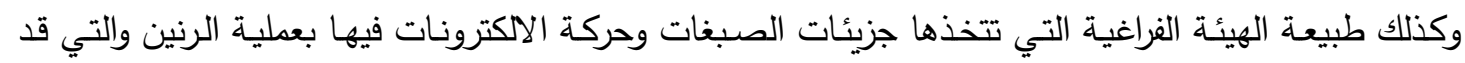
تسير على طول الجزيئة أو على جزء منها بالاعتماد على استوائية الجزيئة وطبيعة تعاقب الأواصر المزدوجة فيها فضلاً عن الإعاقة الفراغية فيها. 
الاراسة الثرموداينميكية:

تعد الدراسة الثرموداينميكية لنظام الامتزاز ضرورة ملحة للتعرف على طبيعة النظام المدروس ومقياسا لطبيعة القوى التي تتحكم فيه والمسيرة لعملية الامتزاز فضلاً عن أنها تمكننا من إعطاء فكرة عن نوع التداخلات الجزيئية التي يمكن أن تحدث خلال عملية الامتزاز والتي لها دور كبير في تحديد كفاءته. وقد حسبت قيم الدوال

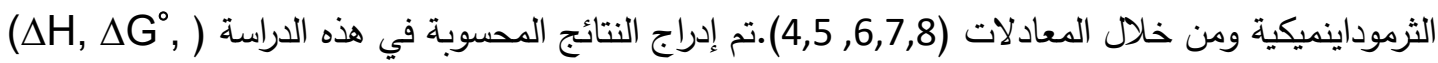
1/T في الجداول (9,10) بين الثكل (4,5) العلاقات الخطية الناتجة من رسم LnK مقابل عند تطبيق من معادلة فانت هوف المستعملة لحساب قيم التغير في الانثالبي.

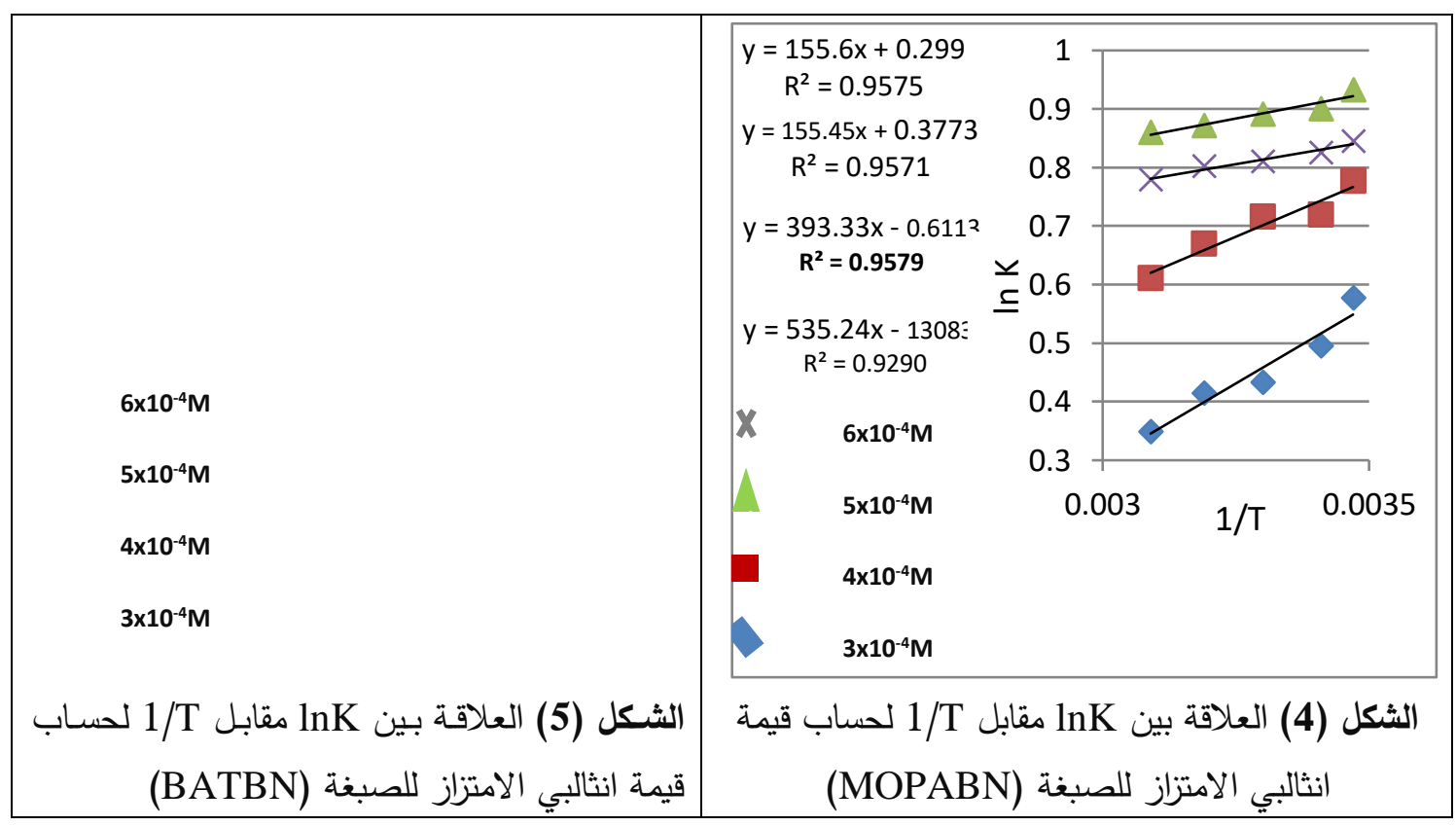


الجدول (9) قيم ثوابت الاتزان والدوال الثرموداينميكية عند الاتزان لامتزاز المركب (MOPABN) ووزن

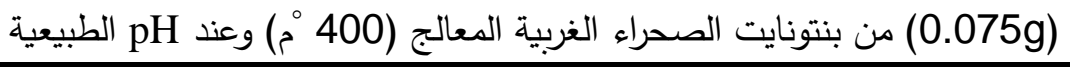

\begin{tabular}{|c|c|c|c|c|c|c|}
\hline Ci(mg/l) & $\operatorname{Temp}\left(K^{\circ}\right)$ & $\mathbf{K}$ & $\begin{array}{c}\Delta \mathrm{H} \\
\left(\mathrm{kj.} . \mathrm{mol}^{-1}\right) \\
\end{array}$ & $\begin{array}{c}\Delta \mathrm{G}^{\circ} \\
\left(\mathrm{kj} . \mathrm{mol}^{-1}\right)\end{array}$ & $\begin{array}{c}\Delta \mathbf{S}^{\circ} \\
\left(\mathbf{j} . \mathrm{mol}^{-1} \cdot \mathrm{k}^{-1}\right)\end{array}$ & $\begin{array}{c}\Delta \mathbf{S} \\
\left(\mathbf{j} \cdot \mathrm{mol}^{-1} \mathrm{k}^{-1}\right) \\
\end{array}$ \\
\hline \multirow{5}{*}{$6 \times 10^{-4}$} & 288 & 2.33 & \multirow{5}{*}{-1.293} & -2.023 & 2.534 & -4.489 \\
\hline & 293 & 2.283 & & -2.009 & 2.443 & -4.412 \\
\hline & 303 & 2.25 & & 2.040 & 2.465 & -4.267 \\
\hline & 313 & 2.23 & & -2.087 & 2.536 & -4.130 \\
\hline & 323 & 2.18 & & -2.091 & 2.470 & -4.003 \\
\hline \multirow{5}{*}{$5 \times 10^{-4}$} & 288 & 2.518 & \multirow{5}{*}{-1.291} & -2.210 & 3.190 & -4.482 \\
\hline & 293 & 2.460 & & -2.192 & 3.075 & -4.406 \\
\hline & 303 & 2.44 & & -2.244 & 3.145 & -4.260 \\
\hline & 313 & 2.390 & & -2.26 & 3.095 & -4.124 \\
\hline & 323 & 2.364 & & -2.309 & 3.151 & -3.996 \\
\hline \multirow{5}{*}{$4 \times 10^{-4}$} & 288 & 2.175 & \multirow{5}{*}{-3.311} & -1.865 & -5.020 & -11.49 \\
\hline & 293 & 2.072 & & -1.775 & -5.242 & -11.30 \\
\hline & 303 & 2.046 & & -1.801 & -4.983 & -10.92 \\
\hline & 313 & 1.954 & & -1.746 & -4.807 & -10.57 \\
\hline & 323 & 1.842 & & -1.638 & -5.195 & -10.25 \\
\hline \multirow{5}{*}{$3 \times 10^{-4}$} & 288 & 1.782 & \multirow{5}{*}{-4.449} & -1.381 & -10.65 & -15.44 \\
\hline & 293 & 1.642 & & -1.205 & -11.07 & -15.18 \\
\hline & 303 & 1.542 & & -1.090 & -11.08 & -14.68 \\
\hline & 313 & 1.514 & & -1.077 & -10.77 & -14.21 \\
\hline & 323 & 1.419 & & -0.937 & -10.87 & -13.77 \\
\hline
\end{tabular}


الجدول (10) قيم ثوابت الاتزان والدوال الثرموداينميكية عند الاتزان لامتزاز المركب (BTABN) ووزن

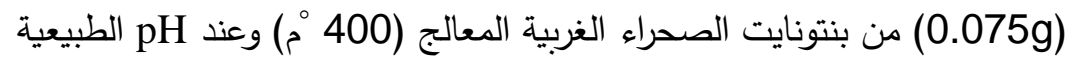

\begin{tabular}{|c|c|c|c|c|c|c|}
\hline $\mathrm{Ci}(\mathrm{mg} / \mathrm{l})$ & $\operatorname{Temp}\left(K^{\circ}\right)$ & $\mathbf{K}$ & $\begin{array}{c}\mathbf{H} \\
\left(\mathrm{kj} \cdot \mathrm{mol}^{-1}\right)\end{array}$ & $\begin{array}{c}\Delta \mathrm{G}^{\circ} \\
\left(\mathrm{kj.mol}^{-1}\right)\end{array}$ & $\begin{array}{c}\Delta \mathbf{S}^{\circ} \\
\left(\mathbf{j} . \mathrm{mol}^{-1} \cdot \mathrm{k}^{-1}\right) \\
\end{array}$ & $\begin{array}{c}\mathbf{S} \\
\left(\mathbf{j} \cdot \mathrm{mol}^{-1} \mathrm{k}^{-1}\right) \\
\end{array}$ \\
\hline \multirow{5}{*}{$6 \times 10^{-4}$} & 288 & 2.69 & \multirow{5}{*}{-2.131} & -2.368 & 0.822 & -7.399 \\
\hline & 293 & 2.59 & & -2.316 & 0.630 & -7.273 \\
\hline & 303 & 2.58 & & -2.385 & 0.838 & -7.033 \\
\hline & 313 & 2.50 & & -2.383 & 0.805 & -7.808 \\
\hline & 323 & 2.41 & & -2.360 & 0.708 & -6.597 \\
\hline \multirow{5}{*}{$5 \times 10^{-4}$} & 288 & 2.73 & \multirow{5}{*}{-2.697} & -2.420 & -0.961 & -9.364 \\
\hline & 293 & 2.58 & & -2.260 & -1.491 & -9.204 \\
\hline & 303 & 2.51 & & -2.317 & -1.254 & -8.900 \\
\hline & 313 & 2.50 & & -2.383 & -1.003 & -8.616 \\
\hline & 323 & 2.36 & & -2.304 & -1.216 & -8.349 \\
\hline \multirow{5}{*}{$4 \times 10^{-4}$} & 288 & 2.06 & \multirow{5}{*}{-2.310} & -1.728 & -2.020 & -8.020 \\
\hline & 293 & 1.94 & & -1.612 & -2.382 & -7.883 \\
\hline & 303 & 1.93 & & -1.655 & -2.161 & -7.623 \\
\hline & 313 & 1.89 & & -1.655 & -2.092 & -7.380 \\
\hline & 323 & 1.82 & & -1.605 & -2.182 & -7.151 \\
\hline \multirow{5}{*}{$3 \times 10^{-4}$} & 288 & 1.71 & \multirow{5}{*}{-2.820} & -1.290 & -5.312 & -9.791 \\
\hline & 293 & 1.63 & & -1.188 & -5.569 & -9.624 \\
\hline & 303 & 1.61 & & -1.199 & -5.349 & -9.306 \\
\hline & 313 & 1.56 & & -1.155 & -5.319 & -9.006 \\
\hline & 323 & 1.48 & & -1.052 & -5.473 & -8.730 \\
\hline
\end{tabular}

عند النظر إلى الأشكال نجدها علاقات خطية جيدة ويستدل على ذلك من قيم معامل الارتباط (R²) وعند معظم الدرجات الحرارية والتراكيز الابتدائية المختلفة والمختارة لهذه الدراسة .ومن خلال متابعة وتدقيق قيم الائ 
الدوال الثرموداينميكية $)$ (

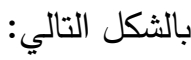

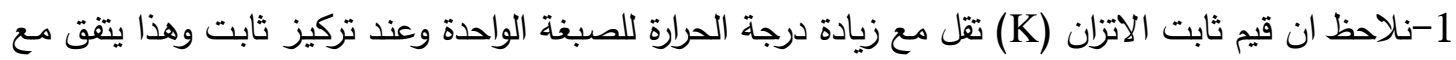

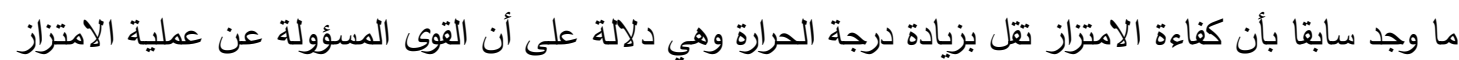
ذات طبيعة فيزيائية.

2-إن قيم التغير في الانثالبي (UH) والتي حسبت في مدى من الدرجات الحراريـة بين (288-323 مطلقة)

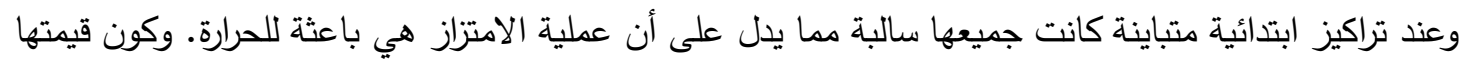

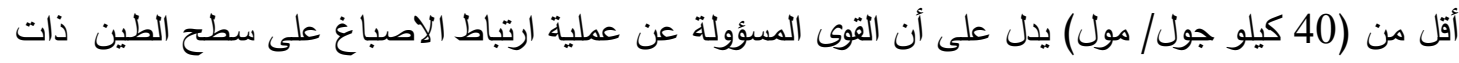

طبيعية فيزيائية.

3- لغرض متابعة التغير في قيمة الانتروبي فقد تم حساب قيمتين لها:

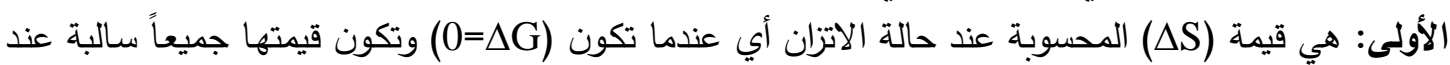

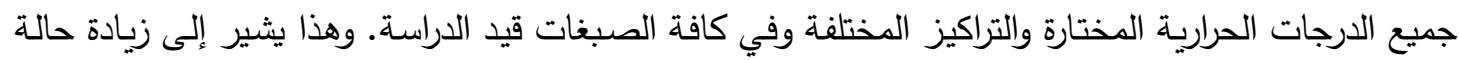

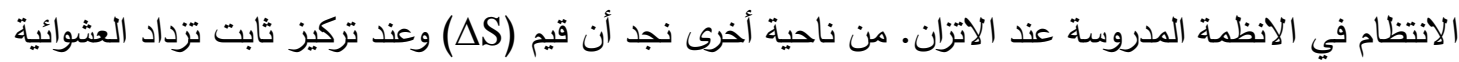

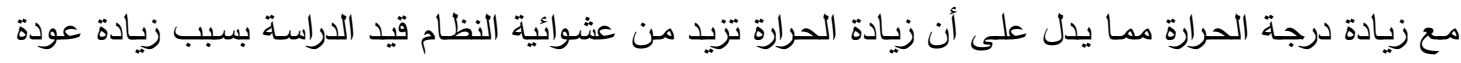

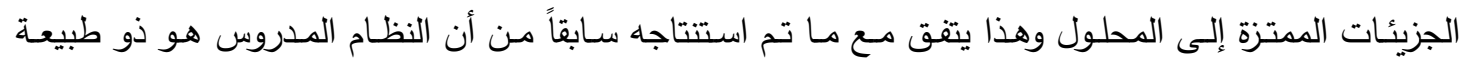

فيزيائية.

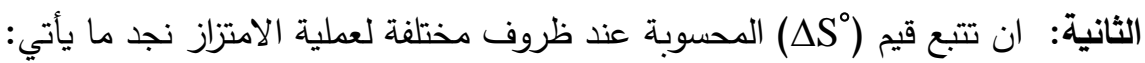

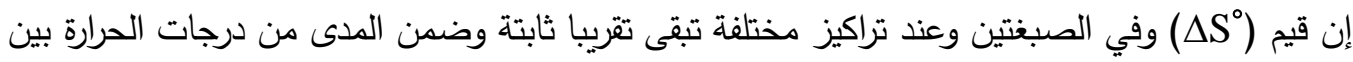
(288-323 مطلقة) والذي اختير في إنجاز هذه الدراسة.

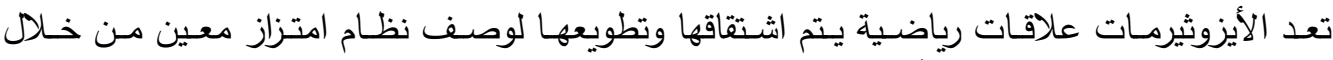

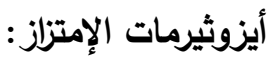

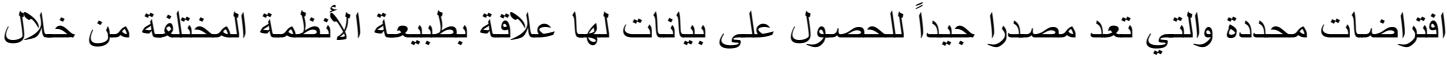

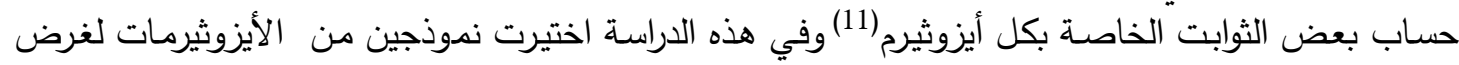

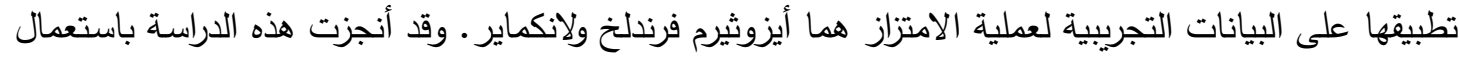

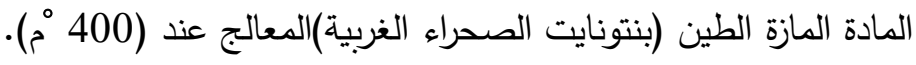

أيزوثيرم لانكماير:

وقد طبق هذا الأيزوثيرم على البيانات العملية لامتزاز الصبغات قيد الدراسـة على المادة المازة وعند

الاتزان وذلك برسم العلاقة بين (Ce/ 


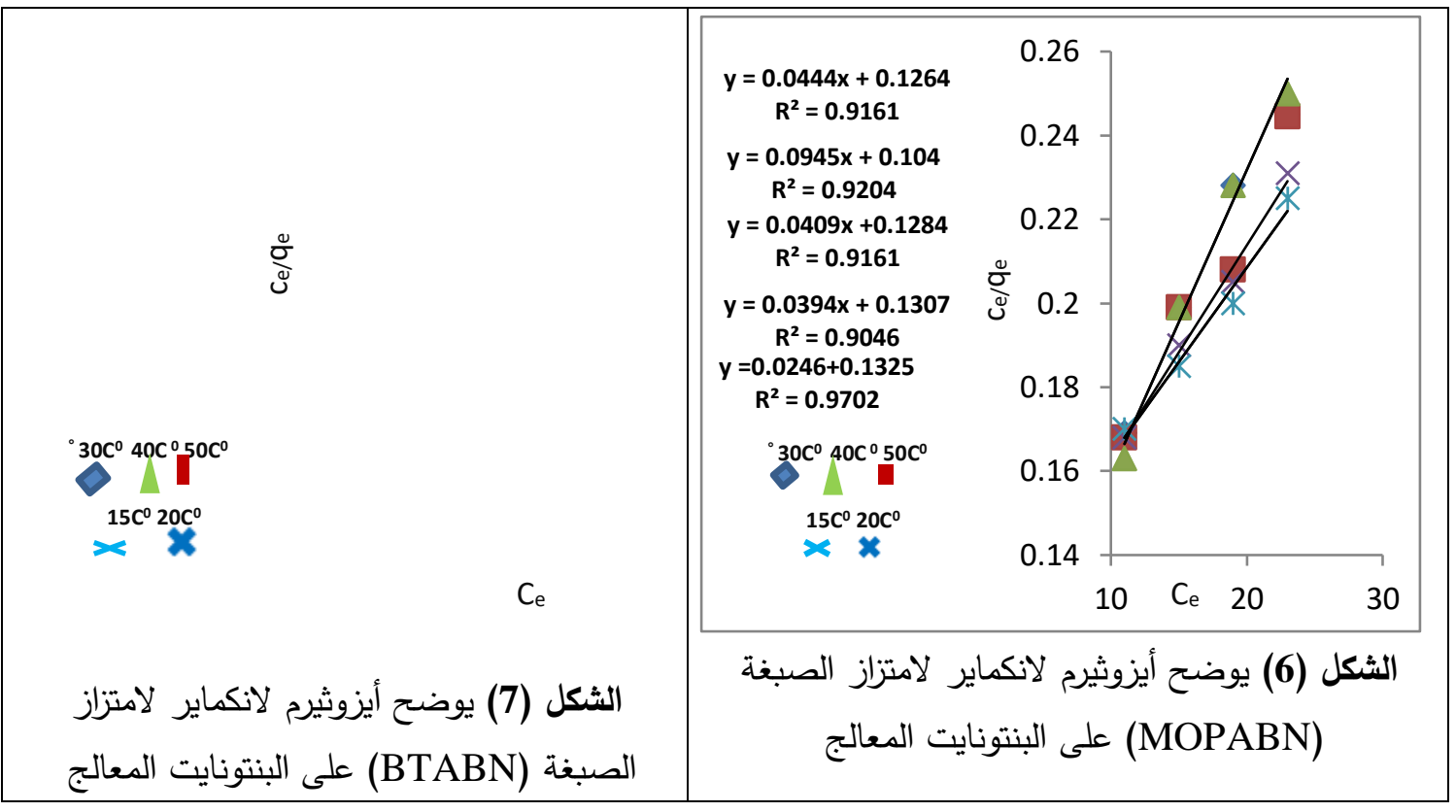

الجدول (11) يوضح ثوابت لانكماير ( Q Qmax) ومعاملات الارتباط التي حصلت على البيانات العملية للامتزاز

\begin{tabular}{|c|c|c|c|c|}
\hline اسم المركب & $\operatorname{Temp}\left(K^{\circ}\right)$ & b (L/mg) & $\begin{array}{c}Q_{\max } \\
(\mathrm{mg} / \mathrm{g})\end{array}$ & $\mathbf{R}$ \\
\hline \multirow{5}{*}{ MOPABN } & 288 & 0.064 & 156.25 & 0.9818 \\
\hline & 293 & 0.064 & 166.6 & 0.9772 \\
\hline & 303 & 0.061 & 181.8 & 0.9919 \\
\hline & 313 & 0.045 & 200.0 & 0.9984 \\
\hline & 323 & 0.038 & 222.2 & 0.9486 \\
\hline \multirow{5}{*}{ BTABN } & 288 & 0.044 & 200.0 & 0.9746 \\
\hline & 293 & 0.032 & 250.0 & 0.9705 \\
\hline & 303 & 0.017 & 263.0 & 0.9726 \\
\hline & 313 & 0.014 & 333.3 & 0.9751 \\
\hline & 323 & 0.012 & 357.1 & 0.9939 \\
\hline
\end{tabular}

من خلال الجدول (11) يمكن ادراج النقاط الآتية:

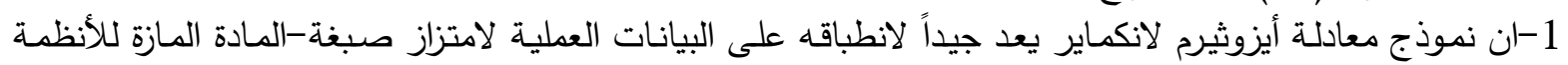

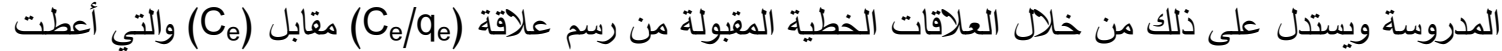

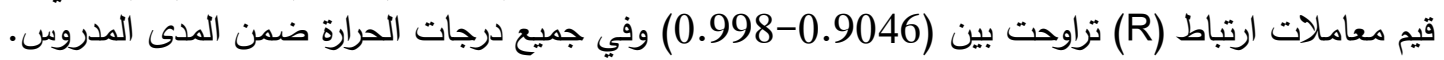

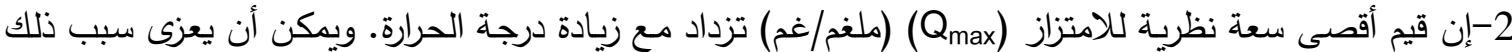

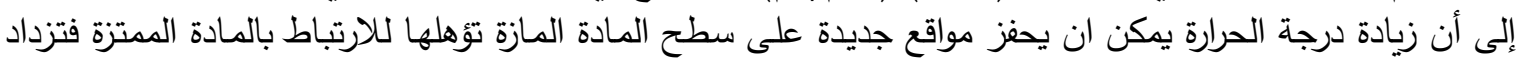

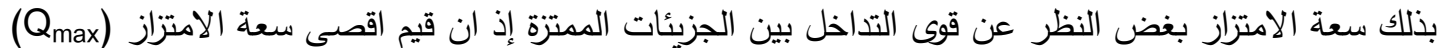

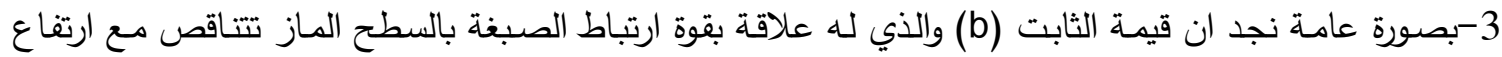

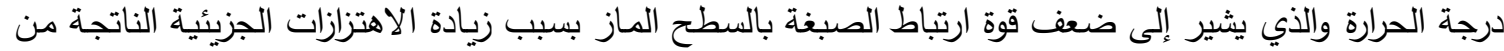

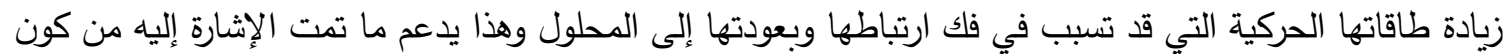

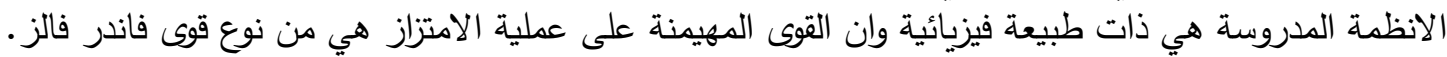




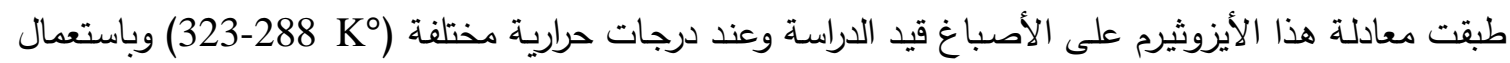

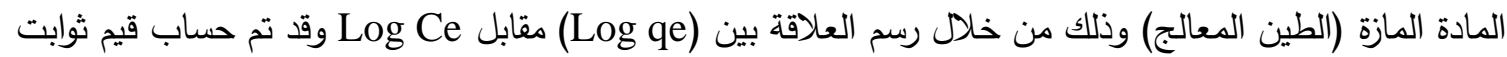

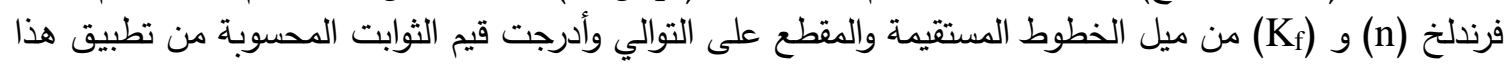
الأيزوثيرم في الجدول رقم (12) وكانت كالآتي.

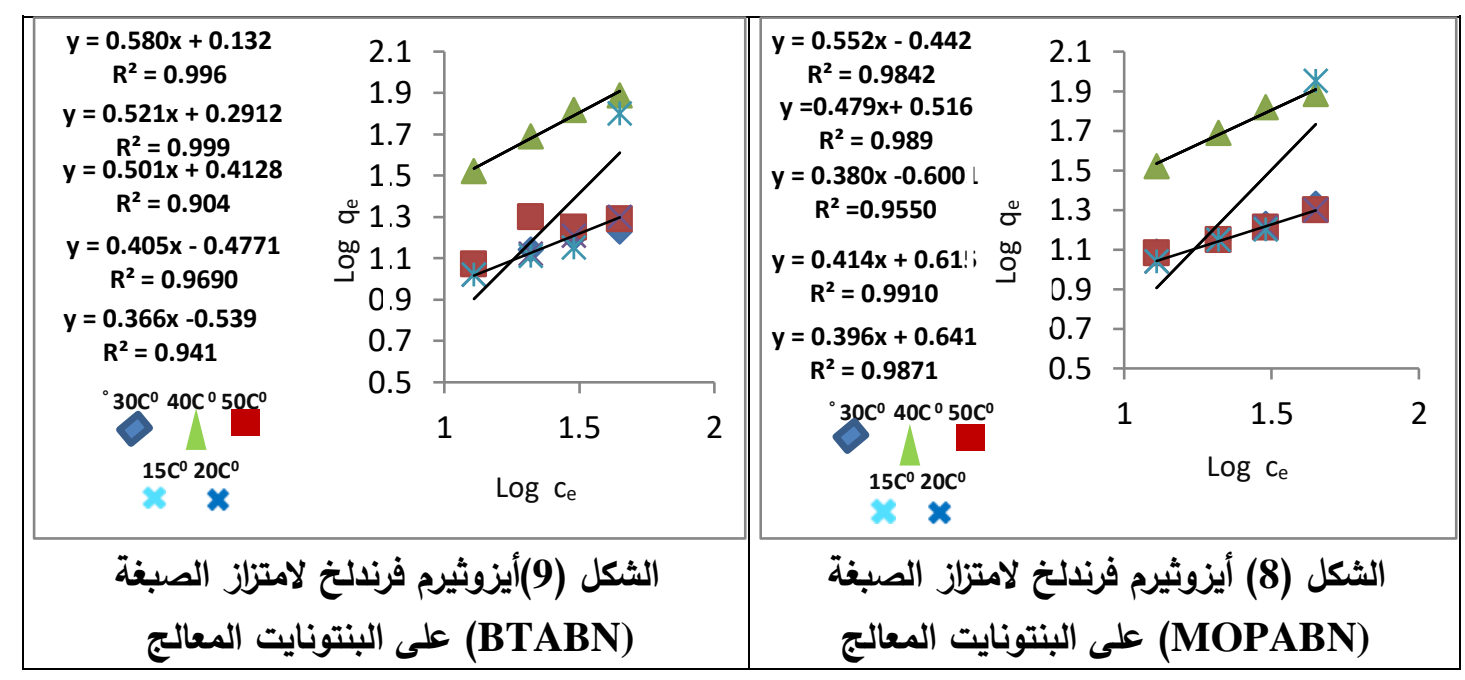

الجدول (12) قيم ثوابت فرندلخ (Kf,n) ومعاملات الارتباط التي حصلت من تطبيقها على البيانات العلمية للامتزاز

\begin{tabular}{|c|c|c|c|c|}
\hline \hline & Temp $^{\circ}$ & $\mathrm{n}$ & $\mathrm{K}_{\mathbf{f}}$ & $\mathbf{R}$ \\
\hline \multirow{4}{*}{ MOPABN } & $\mathbf{1 5}$ & $\mathbf{2 . 5 2}$ & $\mathbf{4 . 3 8 1}$ & $\mathbf{0 . 9 9 3 4}$ \\
\cline { 2 - 5 } & $\mathbf{2 0}$ & $\mathbf{2 . 4 1}$ & $\mathbf{4 . 1 4 2}$ & $\mathbf{0 . 9 9 5 4}$ \\
\cline { 2 - 5 } & $\mathbf{3 0}$ & $\mathbf{2 . 6 3}$ & $\mathbf{3 . 9 8 1}$ & $\mathbf{0 . 9 7 7 2}$ \\
\cline { 2 - 5 } & $\mathbf{4 0}$ & $\mathbf{2 . 0 8}$ & $\mathbf{3 . 2 9 6}$ & $\mathbf{0 . 9 9 4 4}$ \\
\cline { 2 - 5 } & $\mathbf{5 0}$ & $\mathbf{1 . 8 1}$ & $\mathbf{2 . 7 7 0}$ & $\mathbf{0 . 9 9 2 0}$ \\
\hline \multirow{4}{*}{ BTABN } & $\mathbf{1 5}$ & $\mathbf{2 . 7 2}$ & $\mathbf{3 . 4 5 9}$ & $\mathbf{0 . 9 5 0 8}$ \\
\cline { 2 - 5 } & $\mathbf{2 0}$ & $\mathbf{2 . 4 7}$ & $\mathbf{2 . 9 9 9}$ & $\mathbf{0 . 9 8 4 4}$ \\
\cline { 2 - 5 } & $\mathbf{3 0}$ & $\mathbf{1 . 9 9}$ & $\mathbf{2 . 5 8 7}$ & $\mathbf{0 . 9 5 0 7}$ \\
\cline { 2 - 5 } & $\mathbf{4 0}$ & $\mathbf{1 . 9 1}$ & $\mathbf{1 . 9 5 4}$ & $\mathbf{0 . 9 9 9 4}$ \\
\cline { 2 - 5 } & $\mathbf{5 0}$ & $\mathbf{1 . 7 2}$ & $\mathbf{1 . 3 5 2}$ & $\mathbf{0 . 9 9 7 9}$ \\
\hline
\end{tabular}

من خلال ملاحظة قيم النتائج التي تم الحصول عليها في الجدول (12) نجد ما يأتي:

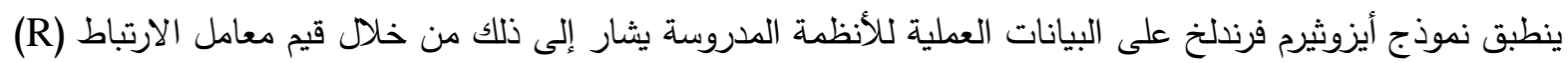

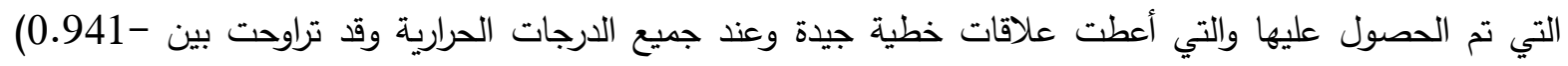

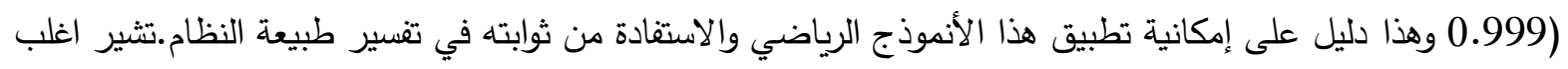

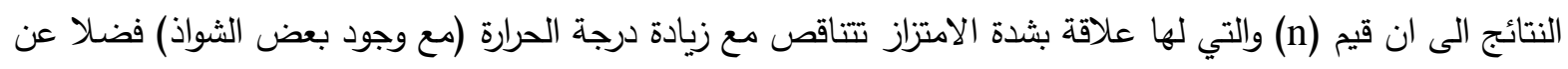

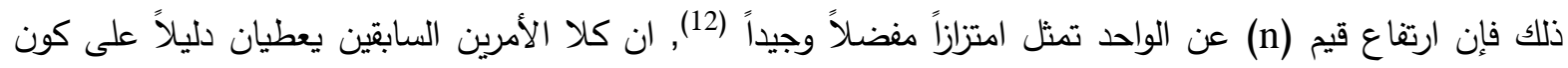

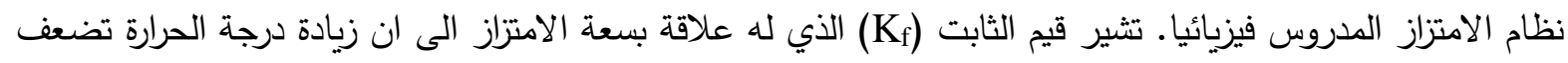

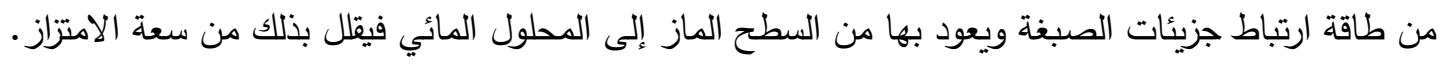




$$
\text { الجدول (13) يوضح حزم بعض الامتصاصات المهمة في طيف الأشعة تحت الحمر اء (سم-1) }
$$

\begin{tabular}{|c|c|c|c|c|c|c|c|}
\hline Dye & $\begin{array}{c}\text { S-H } \\
\text { Sحول }\end{array}$ & $\begin{array}{c}\text { D } \\
N=N\end{array}$ & $\begin{array}{c}\text { م-O } \\
\text { C-O }\end{array}$ & $\begin{array}{c}\text { اروماتي } \\
\text { C-H }\end{array}$ & $\begin{array}{c}\text { اليفاتي } \\
\text { C-H }\end{array}$ & النغمات التوافقية & أخزى الهزات \\
\hline $\begin{array}{c}1 \text { (4-methoxy } \\
\text { phenyl) } \\
\text { azo-2-Naphtho } \\
\text { (MOPABN) }\end{array}$ & 3371 & 1380 & 1213 & 3029 & 2820 & $\begin{array}{l}1170 \\
1139\end{array}$ & - \\
\hline $\begin{array}{l}\text { 2- (enzothiazol } 1 \\
\text { azo-2-naphthol) } \\
\text { (BTABN) }\end{array}$ & 3380 & 1342 & 1205 & 3008 & 2854 & $\begin{array}{l}1155 \\
1130\end{array}$ & $\begin{array}{c}3417 \\
(\mathrm{~N}-\mathrm{H}) \\
1950 \\
(\mathrm{~S}-\mathrm{H})\end{array}$ \\
\hline
\end{tabular}

المصادر

1. Emad. A. AL-Hyali, O. M. Ramadhan and S. A. AL- Dobone, "Effect of substituents type on the adsorption of aromatic carboxylic acid and their relation to concentration, temperature and pH", Raf. Jour. Sci., vol. 16, No. 3, pp. 6878(2005).

2. Team. H. Wallace, "Biological treatment of synthetic dye water and an industrial textile wastewater containing azo dya compounds", Blak burg Virginia(2001).

3. Smeth. K, S. N. Upadhyay and Y. D. Upadhya, "Removal of phenols of adsorption on fly ash", J. Chem. Tech. Biotechnol., 37, pp. 281-290,(1987).

4. T. O. Ryabukhova, S. Arzamaa, A. B. Okishevana and S. N. Konovalova, "Adsorption of alcohol's from binary solution on activated carbons", Russian J. of Physical Chemistry, 74, 2, pp.281-283, (2000).

5. I. Vogel, "A Textbook of practical organic chemistry", $3^{\text {rd }}$ ed., Longmans, Green and Co. Ltd., London, pp. 622- 623(1964).

6. Y. Bulut, N. Gozubenli, H. Aydm, "Equilibrium and kinetics studies of adsorption of direct blue 71 from aqueous solution by wheat shells", J. Hazard. Mater., 144, pp. 303-305(2007).

7. Beter. S. Inbaraj, J. T. Chien, G. H. HO, J. Yang and B. H. Chen, "Equilibrium and kinetic studies on sorption of basic dyes by a natural biopolymer poly $(\gamma-$ glutamic acid)", J. Biochemistry and Eng. 31. pp. 209-211(2006)

8. S. S. Reddy, B. Kotaiah, N. S. P. Reddy, M. Velu, "The removal of composite reactive dye from dyeing unit effluent using sewage sludge derived from activated carbon" Turk. J. Eng. Env. Sci., 30, 370(2006).

9. Aiman S. M. T., M.Sc. Shndala.Thesis, College of Education, University of Mosul(2012).(In Arabic) 
10.Raiad.T.Alabade.,Ph.D. College of Education, University of Mosul(2010) .(In Arabic)

11. S. Knaebel Kent, "Adsorbent selection", Adsorption Research, Inc., Dublin, Ohio, 43016, pp. 1-23(2003).

12. C. H. Wu, "Adsorption of reactive dyes onto carbon nanotubes: Equilibrium, Kinetics and thermodynamics", J. Hazard. Mater., 144, pp. 96-98, (2007). 